\title{
Numerical modeling of mixed sediment resuspension, transport, and deposition during the March 1998 episodic events in southern Lake Michigan
}

\author{
Cheegwan Lee, ${ }^{1}$ David J. Schwab, ${ }^{2}$ Dmitry Beletsky, ${ }^{3}$ Jonathan Stroud, ${ }^{4}$ and Barry Lesht ${ }^{5}$
}

Received 27 November 2005; revised 19 September 2006; accepted 28 September 2006; published 17 February 2007.

[1] A two-dimensional sediment transport model capable of simulating sediment resuspension of mixed (cohesive plus noncohesive) sediment is developed and applied to quantitatively simulate the March 1998 resuspension events in southern Lake Michigan. Some characteristics of the model are the capability to incorporate several floc size classes, a physically based settling velocity formula, bed armoring, and sediment availability limitation. Important resuspension parameters were estimated from field and laboratory measurement data. The model reproduced the resuspension plume (observed by the SeaWIFS satellite and field instruments) and recently measured sedimentation rate distribution (using radiotracer techniques) fairly well. Model results were verified with field measurements of suspended sediment concentration and settling flux (by ADCPs and sediment traps). Both wave conditions and sediment bed properties (critical shear stress, fine sediment fraction, and limited sediment availability or source) are the critical factors that determine the concentration distribution and width of the resuspension plume. The modeled sedimentation pattern shows preferential accumulation of sediment on the eastern side of the lake, which agrees with the observed sedimentation pattern despite a predominance of particle sources from the western shoreline. The main physical mechanisms determining the sedimentation pattern are (1) the two counter-rotating circulation gyres producing offshore mass transport along the southeastern coast during northerly wind and (2) the settling velocity of sediment flocs which controls the deposition location.

Citation: Lee, C., D. J. Schwab, D. Beletsky, J. Stroud, and B. Lesht (2007), Numerical modeling of mixed sediment resuspension, transport, and deposition during the March 1998 episodic events in southern Lake Michigan, J. Geophys. Res., 112, C02018, doi:10.1029/2005JC003419.

\section{Introduction}

[2] Many estuarine, lake and river waters have significant water quality problems which are often related to fine-grained sediment that has a harmful effect on the ecosystem, often carrying contaminants and reducing light needed for primary production. Better prediction of sediment resuspension, transport, and redistribution is of great importance for integrated water and ecosystem management.

[3] Recently, significant attention has been drawn to the resuspension plume of fine-grained sediment in

\footnotetext{
${ }^{1}$ Pacific Northwest National Laboratory/Battelle, Marine Science Laboratory, Seattle, Washington, USA.

${ }^{2}$ Great Lakes Environmental Research Laboratory, NOAA, Ann Arbor, Michigan, USA.

${ }^{3}$ CILER, SNRE, University of Michigan, Ann Arbor, Michigan, USA.

${ }^{4}$ Department of Statistics, University of Pennsylvania, Philadelphia, Pennsylvania, USA.

${ }^{5}$ Argonne National Laboratory, Argonne, Illinois, USA.

Copyright 2007 by the American Geophysical Union. 0148-0227/07/2005JC003419
}

southern Lake Michigan [Eadie et al., 1984; Eadie and Robbins, 1987; Brooks and Edgington, 1994]. Satellite observations of visible reflectance show a welldeveloped resuspension plume extending about $300 \mathrm{~km}$ along the southern Lake Michigan coast with a width of about $10 \mathrm{~km}$. The original source of the resuspended materials is primarily shoreline erosion from the western coast of lake. The sediment contribution to the lake varies widely from one section of shoreline to another, but most of the fine-grained material originates in southern Wisconsin [Monteith and Sonzogni, 1976]. However, sediment resuspension in the coastal zone during a strong storm event far exceeds the fluxes of new material from shoreline erosion and small tributary contributions. During the resuspension events, the suspended materials are transported along the southern coast and permanently deposited in the region offshore of the southeastern coast of the lake.

[4] Approximately $30 \%$ of the lake bottom in the coastal area $(<\sim 30 \mathrm{~m})$ is nondepositional [Lesht and Hawley, 1987; Lesht, 1989]. It appears that the nondepositional area serves as temporary repository for sediments before permanent burial. In the nondepositional region, bottom sediment 
typically consists of a small fraction $(<10 \%)$ of fine-grained materials mixed in the top sandy layer, pebble or bedrock. In the remaining depositional region $(>\sim 30 \mathrm{~m})$ there is a higher percentage of fine-grained materials $(>10 \%)$; see Figure 1. Generally, the fraction of fine-grained materials is fairly well correlated with water depth in these regions [Eadie and Lozano, 1999].

[5] Some studies of fine-grained sediment transport in southern Lake Michigan have been conducted using an integrated hydrodynamic, wind-wave, and sediment transport model [Lou et al., 2000; Schwab et al., 2000]. These studies illustrate that the resuspended sediment plume is usually initiated by a major storm with strong northerly winds generating large waves in southern Lake Michigan. The resuspended sediment is transported by wind-induced currents, and occasionally veers offshore into deeper water somewhere along the eastern shore of the lake near the areas of highest measured long-term sediment accumulation. Previous simulations qualitatively reproduced the coastal plume for episodic events but did not reproduce quantitative details of the plume and observed long-term deposition patterns.

[6] Thanks to considerable progress in hydrodynamic modeling for Lake Michigan, numerical hydrodynamic and wave models are now able to simulate large-scale circulation and fetch-limited wave parameters with reasonable accuracy [Schwab et al., 1984; Liu et al., 1984; Beletsky et al., 2003]. In sediment transport modeling, uncertainty in bed stress estimation using a simple bottom boundary layer model may be a reason for the failure in detailed, quantitative reproduction of sedimentation patterns but the errors can be reduced by proper calibration using measured wave data. Some possible reasons for remaining inaccuracies may be (1) the lack of some important aspects of mixed sediment dynamics in the sediment transport and bed model, (2) spatial and temporal variation of bed properties, and (3) availability of fine sediments mixed in an active sandy bed layer. A recent sensitivity study for resuspension parameters [Lee et al., 2005] indicated that the initial bed conditions (finegrained sediment fraction and availability, and critical bed shear stress) with mixed sediment and settling velocity of fine particles are crucial for improving a quantitative prediction.

[7] The objective of this paper is to quantitatively reproduce the observed resuspension plume during the spring of 1998 and the measured sedimentation patterns using a newly developed, two-dimensional, mixed sediment transport model. The resuspension events in the spring of 1998 were the largest events on record and were well observed by satellite and field measurements during a multidisciplinary research program, Episodic Events Great Lakes Experiment (EEGLE) (Great Lakes Environmental Research Laboratory, NOAA, Ann Arbor, Michigan, http:// www.glerl.noaa.gov/eegle). The sediment transport model is capable of dealing with mixed sediment and size distribution effects. In the model the erosion rate depends on the fine sediment fraction, fine sediment availability, bed armoring by sand, and differential settling. The simulation results are compared quantitatively with the observed satellite images and field measurements of sus-

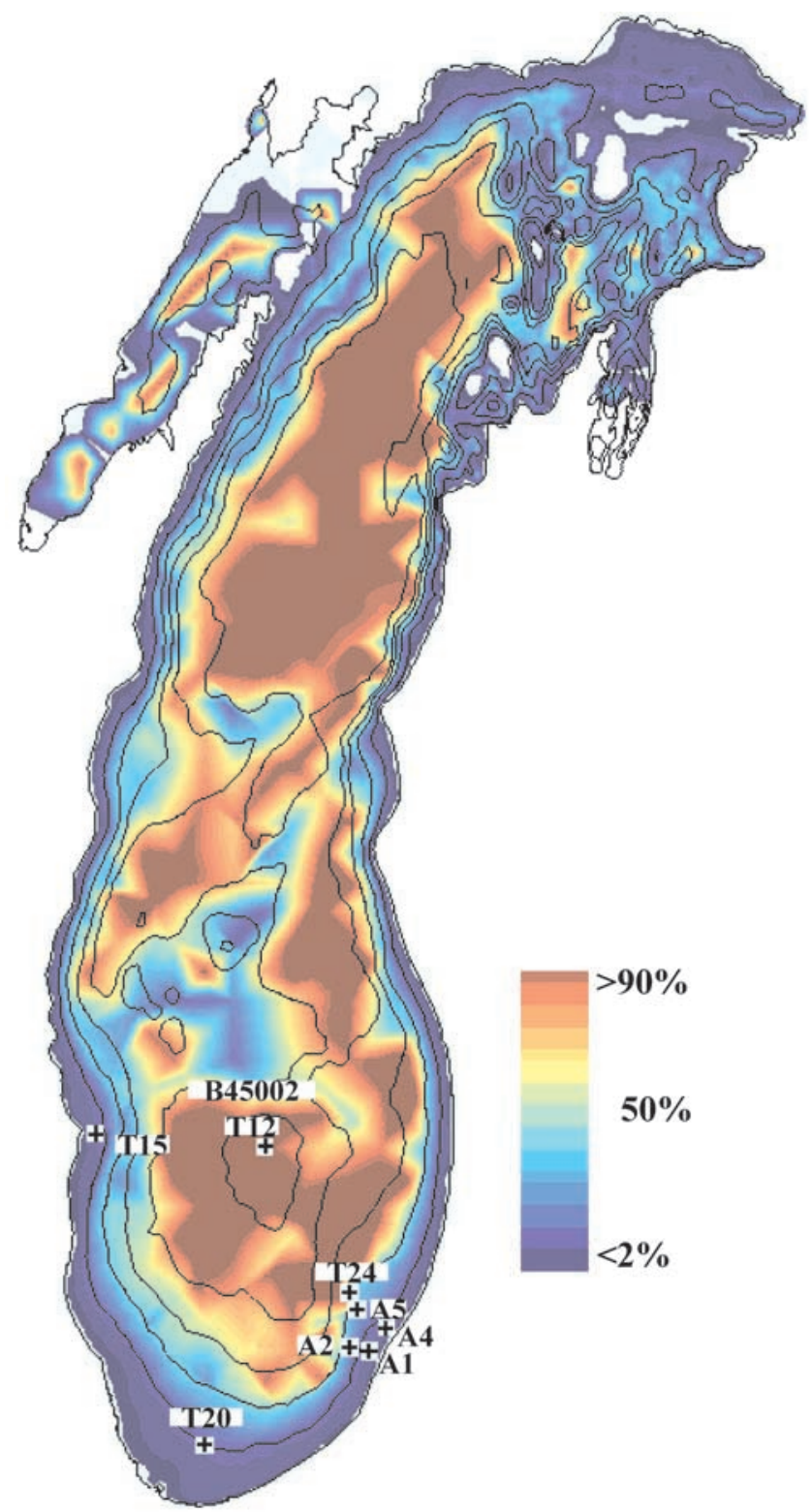

Figure 1. Lake Michigan: percentage of fine grain sediment and location of instrument moorings.

pended sediment concentration, settling flux, and the sediment deposition pattern.

\section{Model Development and Descriptions}

2.1. Hydrodynamics and Wave Models

[8] A three-dimensional circulation model for the Great Lakes [Beletsky et al., 2003] was used to calculate lake circulation. The model is based on the Princeton Ocean Model [Blumberg and Mellor, 1987] that solves the nonlinear, hydrostatic, three-dimensional, primitive equations using a finite difference method. The model uses timedependent wind stress and heat flux forcing at the water surface, free-slip lateral boundary condition, and quadratic bottom friction. The drag coefficient in the bottom friction formulation is calculated based on the assumption of a 
logarithmic bottom boundary. Horizontal mixing is parameterized by the Smagorinsky method [Smagorinsky, 1963]. The Princeton Ocean Model employs the $\sigma$-coordinate system in the vertical direction. The finite difference scheme is second-order and centered in space and time (leapfrog). The model includes the Mellor and Yamada [1982] level 2.5 turbulence model. The hydrodynamic model application to Lake Michigan has 20 vertical levels with finer spacing near the surface and the bottom and a uniform horizontal grid size of $2 \mathrm{~km}$. A new, high-resolution bathymetry for Lake Michigan is used in the model [National Geophysical Data Center, 1996]. A parametric, two-dimensional surface wind wave model [Schwab et al., 1984] is used to calculate wave characteristics for use in the sediment transport model. The model solves the wave momentum conservation equation using a finite difference scheme. The wave energy spectrum is parameterized at each computational grid point in terms of total wave energy, peak energy period, and predominant wave direction. This wind wave model was shown to provide excellent estimates of significant wave height and direction for fetch-limited waves [Liu et al., 1984] despite a tendency to underestimate wave periods.

[9] The combined bed shear stress is calculated simply by a sum of wave and current bed shear stress.

$$
\tau_{c w}=\rho u_{*_{c w}}^{2}=\left[\tau_{w m}^{2}+\tau_{c}^{2}\right]^{1 / 2}
$$

where $\tau_{\mathrm{wm}}$ is the maximum wave shear stress, $\tau_{\mathrm{c}}$ is the current shear stress, $\tau_{\mathrm{cw}}$ is the combined shear stress, and $\rho$ is the water density, and $\mathrm{u} *_{\mathrm{cw}}$ is the combined friction velocity. Jonsson [1966] defined

$$
\tau_{w m}=\frac{1}{2} \rho f_{w} u_{w b}^{2}
$$

where $f_{w}$ is the wave friction factor and $u_{w b}$ is the maximum near-bottom wave velocity. The $\mathrm{u}_{\mathrm{wb}}$ is calculated by linear wave theory from the predicted wave parameters. The friction factor $\mathrm{f}_{\mathrm{w}}$ is calculated from the emperical relations for different flow regimes [Swart, 1974; Kamphuis, 1975; Justesen, 1988]. The current shear stress is calculated by an empirical formula defined as

$$
\tau_{c}=\frac{1}{2} \rho C_{b}\left(u^{2}+v^{2}\right)
$$

Assuming logarithmic velocity profile in the current bottom boundary layer, the bottom stress coefficient is given by

$$
C_{b}=\left(\frac{\kappa}{\ln \left(\Delta z / 2 z_{0}\right)}\right)^{2}
$$

where $\kappa$ is the von Karman constant, $\Delta \mathrm{z}$ is the bottom layer thickness of the hydrodynamic model, and $z_{0}$ is the roughness height. In present study, the roughness height is set to $4 d_{50}$, where $d_{50}$ is a mean sediment particle size.

\subsection{Sediment Transport Model}

[10] A depth-averaged, two-dimensional, mixed sediment transport model (SEDGL2D) was developed for the simulation in Lake Michigan which is characterized by mixed sediment (cohesive plus noncohesive), limited sediment supply and availability, and lateral flux from shoreline erosion. The model consists of two parts: suspended sediment dynamics and bed model. The suspended sediment dynamics model includes the processes of entrainment, flocculation, and deposition of mixed (cohesive plus noncohesive) sediments. In this modeling study, cohesive sediment represents the fine-grained sediment $(<63 \mu \mathrm{m})$ while noncohesive sediments are fine to medium size sand particles $(63 \sim 500 \mu \mathrm{m})$. The fraction of coarse sand and gravel $(>500 \mu \mathrm{m})$ that moves as bed load are generally insignificant in Lake Michigan, so bed load transport is not considered in the present model. The bed model with six segmented bed layers calculates the subsequent change of bed properties such as critical shear stress of cohesive and noncohesive sediments depending on fine-grained fraction, dry bulk density, bed thickness, bed age, and sediment size fraction of each bed layer. The two models are coupled and exchange sediment mass through erosion and deposition processes. The description of the model is given as

$$
\begin{gathered}
\frac{\partial(H \bar{C})}{\partial t}+\frac{\partial(H u \bar{C})}{\partial x}+\frac{\partial(H \nu \bar{C})}{\partial y}=\frac{\partial}{\partial x}\left(H D_{x} \frac{\partial \bar{C}}{\partial x}\right) \\
+\frac{\partial}{\partial y}\left(H D_{y} \frac{\partial \bar{C}}{\partial y}\right)+\left(F_{R}-F_{D}\right)+F_{L} \\
\frac{\partial z_{b}}{\partial t}=-\frac{1}{\rho_{b}}\left(F_{R}-F_{D}\right)
\end{gathered}
$$

where $\bar{C}$ is the depth averaged concentration, $\mathrm{H}$ is the water depth, $\mathrm{u}, \mathrm{v}$ are depth-averaged velocity, $\mathrm{D}_{\mathrm{x}}$ and $\mathrm{D}_{\mathrm{y}}$ are the turbulent diffusion coefficients, $F_{R}$ is the resuspension flux, $F_{D}$ is the deposition flux, $F_{L}$ is the lateral flux from shoreline erosion and tributaries, $\mathrm{Z}_{\mathrm{b}}$ is the top bed layer thickness, $\rho_{\mathrm{b}}$ is the dry bulk density. A semi-implicit scheme for time differencing, an upwind scheme for the advective terms and central differencing for diffusion terms were used to numerically solve the transport equation.

[11] The linear combination of two discrete equations for cohesive and noncohesive particles is a simple way to describe the complex entrainment processes of a mixture of particles of different size, density, and cohesion. Important mixture effects (dependence of erosion rate on finegrained sediment fraction, sediment availability, and bed armoring) are incorporated into the entrainment formulation to better describe the mixture process. A dependence of erosion rate on fine sediment fraction is obvious in two respects: (1) entrainment probability (depending on turbulent bursting frequency and intensity and sediment fraction ratio) and (2) cohesion force. The fundamental mechanism of sediment entrainment is the turbulent bursting processes (sweep and ejection) randomly distributed over the sediment bed [Kaftori et al., 1995; Niño and Garcia, 1996]. Frequency, spatial density, and intensity of the bursting processes increase with Reynolds number $\left(=\mathrm{u}^{*} \delta / \nu\right)$ in the bottom boundary layer. Therefore, only fine-grained materials or both fine and coarse materials are entrained into suspension at two different rates, swept by a strong turbulent burst exceeding the critical shear stress. Consequently, a winnowing of fine materials from the thin active sandy bed 
layer can quickly result in bed armoring that reduces resuspension [van Niekert et al., 1992; Harris and Wiberg, 2001]. Especially in the coastal region of Lake Michigan where the fine sediment fraction is relatively small and confined to the top sandy layer, the resuspension of fine sediment is strongly limited by its remaining fraction and the thickness of the active sediment layer. Generally, an increase in the fine sediment fraction increases the cohesion force between particles, resulting in a reduced resuspension rate. In this model, the resuspension rate constant $\left(\mathrm{M}_{0}\right)$ was estimated from field measurement data.

[12] Entrainment of mixed sediments is calculated as a fraction-weighted average of two common discrete resuspension equations, Mehta et al.'s [1997] formula for cohesive sediment and Smith and McLean's [1977] formula for noncohesive sediment.

$$
\begin{aligned}
F_{R}= & f_{c s} \sum_{i=1}^{n_{c}}\left[f_{f, i} M_{0}\left(\tau_{b}-\tau_{c, c s}\right)\right] \\
& +\left(1-f_{c s}\right) \sum_{j=1}^{n_{s}}\left[f_{s, j} w_{s, j} f\left(R, z_{r}\right) \bar{C}_{e q, j}\right]
\end{aligned}
$$

where $f_{c s}$ is the fraction of fine-grained sediment, $n_{c}$ is the number of fine-grained size classes, $f_{f, i}$ is the fraction of each fine-grained size ( $\mathrm{i}=$ index of fine-grained size class), $\mathrm{M}_{0}$ is the erosion rate constant, $\tau_{\mathrm{b}}$ is the bed shear stress, $\tau_{\mathrm{c}, \mathrm{cs}}$ is the critical shear stress for cohesive sediment erosion, $n_{s}$ is the number of sand size classes, $f_{s, j}$ is the fraction of each sand size ( $\mathrm{j}=$ index of sand size class), $\mathrm{w}_{\mathrm{s}, \mathrm{j}}$ is the settling velocity of each sand size class, $\mathrm{R}$ is the Rouse number $\left(=\mathrm{w}_{\mathrm{s}} / \mathrm{u}^{*} \kappa\right), \mathrm{z}_{\mathrm{r}}$ is the reference height, $\mathrm{f}\left(\mathrm{R}, \mathrm{Z}_{\mathrm{r}}\right)$ is a conversion function for converting depthaveraged equilibrium concentration to concentration at the reference height (see equation (A8) in Appendix A), and $\bar{C}_{\mathrm{eq}, \mathrm{j}}$ is the depth-averaged equilibrium concentration of each size class of sand. Smith and McLean's [1977] formula provide the $\bar{C}_{\mathrm{eq}, \mathrm{j}}$ as

$$
\begin{gathered}
\bar{C}_{e q, j}=h\left(R, z_{r}\right) \rho_{s} \frac{0.65 \gamma_{0} T_{j}}{1+\gamma_{0} T_{j}} \quad, \gamma_{0}=2.4 \times 10^{-3} \\
T_{j}=\frac{\tau_{b}-\tau_{c, j}}{\tau_{c, j}}
\end{gathered}
$$

where $h\left(R, z_{r}\right)$ is a function for converting the reference concentration at $\mathrm{z}=\mathrm{z}_{\mathrm{r}}$ to the depth-averaged equilibrium concentration (see equation (A9) in Appendix A), $\rho_{\mathrm{s}}$ is the sand density, and $\tau_{\mathrm{c}, \mathrm{j}}$ is the critical shear stress for erosion of each sand class calculated from the Shields parameter. The above conversion functions provide the appropriate boundary flux for the depth-averaged model.

[13] A basic assumption of the mixed sediment deposition model is the discrete settling between cohesive and noncohesive sediments. A combined deposition flux is described in this model as follows:

$$
F_{D}=\sum_{i=1}^{n_{c}}\left[w_{s, i} g\left(R, z_{d}\right) \bar{C}_{i} P_{d, i}\right]+\sum_{j=1}^{n_{s}} w_{s, j} f\left(R, z_{r}\right) \bar{C}_{j}
$$

where $i$ and $j$ are the index of floc and sand size classes respectively, $w_{s}$ is the settling velocity, $g\left(R, z_{d}\right)$ and $f\left(R, z_{r}\right)$ are conversion functions converting the depth-averaged concentration for near-bed concentration at $\mathrm{z}=\mathrm{z}_{\mathrm{d}}$ and $\mathrm{z}_{\mathrm{r}}$ (see equations (A14) and (A15) in Appendix A), $z_{d}$ and $z_{r}$ are the deposition and reference height, $\bar{C}_{\mathrm{i}}$ and $\bar{C}_{\mathrm{j}}$ are the depth-averaged concentrations of fine-grained and sand particles, and $\mathrm{P}_{\mathrm{d}, \mathrm{i}}$ is the deposition probability for finegrained sediment. The detailed derivation can be found in Appendix A and the reference Tetra Tech, Inc. [1999].

[14] A unique feature of the current sediment dynamics model is the use of a physically based, unified settling velocity formula for mixed sediment. For both cohesive and noncohesive sediments, the basic forces determining fall velocity are gravity, buoyancy, skin and form drag forces. The main differences between cohesive and noncohesive sediment are the particle/aggregate density and shape. Generally, the floc density is inversely proportional to floc size, while the density of noncohesive sediment (sand) is invariant (specific gravity equal to 2.65). The shape of a floc is plate-like, while the shape of sand is angular but more spherical. These two parameters in addition to particle size cause a large difference of settling velocity between the two types of sediment, affecting gravity and form drag. In consideration of these factors, the settling velocity of mixed sediments is estimated using a single formula describing the fall velocity of a spherical particle under a wide range of Reynolds numbers as follows [Julien, 1998]:

$$
w_{s}=C_{F D} \frac{8 \nu_{m}}{d_{s}}\left(\left[1+0.0139 d_{*}^{3}\right]^{0.5}-1\right), d_{*}=d_{s}\left[\frac{\left(\rho_{s} / \rho_{w}-1\right) g}{\nu_{m}^{2}}\right]^{1 / 3}
$$

where $\mathrm{w}_{\mathrm{S}}$ is the fall velocity, $\mathrm{C}_{\mathrm{FD}}$ is the effective settling coefficient considering particle shape, pore space and organic contents $\left(\mathrm{C}_{\mathrm{FD}}=1\right.$ for sand, $\mathrm{C}_{\mathrm{FD}}<1$ for a platelike floc), $\nu_{\mathrm{m}}$ is the kinematic viscosity of a mixture (water and sediment), $d_{s}$ is the sediment particle diameter (sand diameter, $\mathrm{d}_{\mathrm{s}}$ can be replaced by floc diameter, $\mathrm{d}_{\mathrm{f}}$, for cohesive sediment); $\rho_{\mathrm{s}}$ is the sediment particle density $\left(=2.65 \mathrm{~g} / \mathrm{cm}^{3}\right.$ for sand and $\rho_{\mathrm{s}}$ can be replaced by floc density, $\rho_{\mathrm{f}}$ for cohesive sediment), $\rho_{\mathrm{w}}$ is the density of water, and $\mathrm{g}$ is the gravity acceleration. $\mathrm{C}_{\mathrm{FD}}$ for a floc is set to 0.3 based on the experimental data showing the effects of fractal dimension (or shape) on the settling velocity [Chakraborti and Atkinson, 2003].

[15] Flocculation processes are parameterized to estimate size $\left(\mathrm{d}_{\mathrm{f}}\right)$, density $\left(\rho_{\mathrm{f}}\right)$, and fraction $\left(\mathrm{f}_{\mathrm{f}, \mathrm{i}}\right)$ of sediment flocs at the deposition level $\left(\mathrm{z}_{\mathrm{d}}\right)$. Assuming the commonly accepted lognormal distribution of floc size class, the probability density (PDF) and cumulative density function (CDF) of fine-grained sediment flocs were developed from Lick and Lick's laboratory data to estimate the fraction and size distribution of sediment flocs. Then the resulting settling velocity spectrum $\left(\mathrm{w}_{\mathrm{s}}\right)$ was calculated from the estimated floc size and density using the settling velocity formula. A detailed explanation of this procedure and the resulting probability functions can be found in Lee et al. [2005].

[16] The probability of cohesive sediment deposition $\left(\mathrm{P}_{\mathrm{d}}\right)$ parameterizes the effects of near-bed turbulence on the deposition rate. The complicated interaction between near- 
bed turbulence structure and particles causes a partial deposition of settling particles [Krone, 1962; Partheniades, 1992]. In the present study, Partheniades's empirical formulation is adopted because it allows a finite deposition to occur even for high shear stress. The formulation is expressed as

$$
\begin{gathered}
P_{d}=1-\frac{1}{\sqrt{2 \pi}} \int_{-\infty}^{Y} e^{-\frac{\omega^{2}}{2}} d \omega \\
Y=2.04 \log \left[0.25\left(\frac{\tau_{b}}{\tau_{c d}-1}\right) e^{12.7 \tau_{c d}}\right]
\end{gathered}
$$

where $\omega$ is a dummy variable and $\tau_{\mathrm{cd}}$ is the critical bed shear stress for deposition below which $\mathrm{P}_{\mathrm{d}}=1(\mathrm{~Pa})$.

[17] Deposition $\left(\mathrm{F}_{\mathrm{S}}\right)$ and resuspension $\left(\mathrm{F}_{\mathrm{R}}\right)$ terms in the transport equation become source and sink terms in the bed model (see equation (6)), adding to or removing from the sediment bed at the net exchange rate. A mass rate of exchange is converted to/from a volumetric rate of change by the bed bulk density. Sediment beds are treated as a sequence of layers, below which is a nonerodible surface. Each layer has its own characteristics: thickness, bulk density, age, and sediment fraction. Based on the above basic characteristics, a second list of characteristics is determined: critical shear stress, erosion rate constant, bulk density. Net sediment deposits build up a surface layer whose thickness does not exceed a specified value $(1.5 \mathrm{~cm})$. When an old surface layer thickness exceeds the specified thickness, a new surface layer is formed. The lowest bottom layer, representing a fully consolidated bed, allows a flexible thickness to conserve the total mass of sediment. Net sediment erosions erode down a surface layer. When the mass of resuspended sediment exceeds the amount in the surface layer, the total resuspended mass is limited to be equal to the mass in the surface layer and then a new layer is exposed to the eroding flow. To avoid less erosion due to very thin surface layer during high flow, the bed model pushes up the bed sediment surface to maintain a certain thickness of the surface layer $(0.3 \mathrm{~cm})$. In this pushing process the sediment characteristics are recalculated based on mass conservation.

[18] Consolidation effects are assumed to be insignificant as resuspension events usually occur in the shallow region where the fine sediment fraction is low $(<10 \%)$ and are mostly confined to the top surface layer. Relatively uniform critical shear stress distribution $(0.05 \sim 0.15 \mathrm{~Pa})$ for cohesive sediment, measured at many places during field experiments, supports our assumption.

[19] Bed armoring can occur due to three reasons: (1) the consolidation of cohesive sediment with sediment depth and time, (2) the deposition of coarse sediments, and (3) the erosion of finer sediments, leaving coarse materials in the surface layer. In the areas of Lake Michigan prone to resuspension, the consolidation effects are not significant. Bed armoring processes due to reasons 2 and 3 are most likely to occur. In order to consider those armoring effects, an active layer thickness (mixing layer thickness, $\delta_{\text {active }}$ ) in the surface bed is calculated by the average of two estimations for cohesive and noncohesive sediments [Harris and
Wiberg, 1997; van Niekert et al., 1992; Harris and Wiberg, 2001]. It is assumed that total resuspension is limited by the amount in this active layer.

$$
\delta_{\text {active }}=f_{c s}\left[0.8\left(\tau_{b}-\tau_{c, \text { cohs }}\right)+6 d_{50}\right]+\left(1-f_{c s}\right)\left[2 d_{50} \frac{\tau_{b}}{\tau_{c, \text { sand }}}\right]
$$

This formulation allows the interaction of depositing and eroding sediments in the discrete active layer penetrated by near-bed turbulence.

\section{Model Setup and Simulation}

\subsection{Meteorological Forcings and Hydrodynamics}

[20] Time series of wind speed and direction during the simulation period (March $1-31,1998$ ) at a point in the middle of the southern basin of Lake Michigan are shown in Figure 2. In March 1998, there were four major wind events, two storms with northerly winds (on the 9th and $21 \mathrm{st}$ ) and two with westerly or southerly winds (on the 13th and $27 \mathrm{th}$ ). The largest wave height in the southern basin occurs during the storm with northerly wind that provides the longest fetch distance.

[21] Highly resolved surface winds (6 km grid) calculated by the Penn State/NCAR 5th generation mesoscale meteorological model (MM5) and also meteorological data from 18 National Weather Service stations (NWS) and National Data Buoy Center (NDBC) buoy 45002 were used to estimate wind and air temperature fields on a regular $2 \mathrm{~km}$ model grid for lake circulation and wind waves. The detailed description of these models is given by Beletsky et al. [2003]. The results of the hydrodynamics and wave models were used to externally drive the sediment transport model for the simulation period from March 1 through 31 in 1998. In early spring, the lake is thermally unstratified and density gradients are negligible. Therefore, the hydrodynamic model calculated hourly depth-averaged currents in a barotropic mode. The model results were verified with measurements from a high-density array of current meters deployed in the southern Lake Michigan [Beletsky et al., 2003].

[22] The wave model computed hourly wave height, period, and direction on the $2 \mathrm{~km}$ computational grid. The time series of computed wave height, period, and direction at a point in the middle of the southern basin are also shown in Figure 2. The combined bed shear stress was estimated from the computed wave and current, providing a bottom boundary condition for the sediment dynamics model.

\subsection{Field Data for Sediment Transport Model}

[23] During March in 1998, instrument moorings were deployed at eight locations in southern Lake Michigan (see Figure 1). Four ADCPs (A1, A2, A4, A5) were moored at $18,38,18$, and $38 \mathrm{~m}$ depths in the southeastern basin where offshore transport of sediment most frequently occurs. The ADCPs, calibrated with nearby sampling measurements and transmissometers data, provided time series of suspended sediment concentration estimated from the acoustic backscattering signal strength [Lee et al., 2005]. The settling fluxes at the middle depth were measured using sediment traps (T12, T15, T20, T24) at locations with 160, 22, 25, 

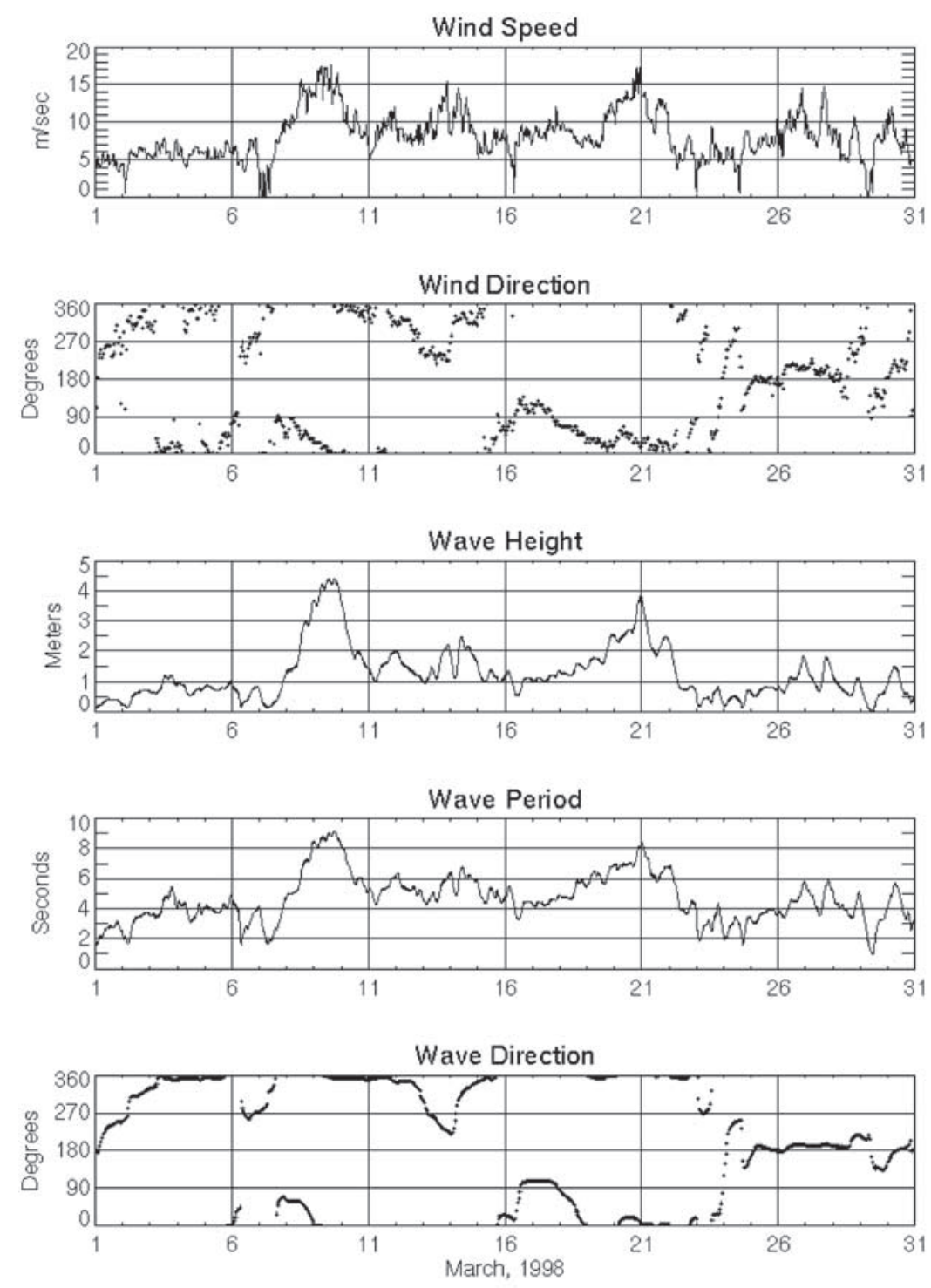

Figure 2. Wind and waves in the middle of southern Lake Michigan.

and $56 \mathrm{~m}$ water depths in 9-day intervals from March 4 to March 31. These measured suspended sediment concentration and fluxes were used to verify the sediment transport model.

[24] Initial distributions of sediment properties (finegrained fraction, critical shear stress, resuspension rate constant, sediment availability) are of critical importance for modeling because the resuspension model depends strongly on those parameters. Often, they are assumed to be homogeneous over a coastal or large lake bed due to lack of field data. In the present study, nonhomogeneites of bed properties were taken into account in the model. We utilized the measured particle size distribution data in the top $1 \mathrm{~cm}$ bed surface over 400 sampling locations that were collected during the Lake Michigan Mass Balance Study (LMMB) [Eadie and Lozano, 1999]. Those data were interpolated onto the hydrodynamic model grid $(2 \mathrm{~km})$ to provide initial fine-grained sediment fractions $(<60 \mu \mathrm{m})$. In shallow regions $(<30 \mathrm{~m})$ the data were insufficient to interpolate accurately so that additional data were added to correlate the fine-grained fraction to water depth in southern Lake
Michigan (Figure 3). This correlation curve was used to generate the fine-grained fraction data in shallow regions. The uncertainty from the interpolated data could cause up to about $50 \%$ error in local suspended fine-grained sediment concentration along the southeastern coast assuming no advection effect [Lee et al., 2005].

[25] The critical shear stress for mixed sediment is not well known due to lack of observational studies. It is different from nonmixed sediment because the cohesive sediments bond together or fill the pore spaces between the angular sand particles to reduce the coarse grain friction more or less [Torfs, 1995]. However, discrete estimation of critical shear stress may be applicable to the shallow water region where the fraction of cohesive sediment is small like coastal water in Lake Michigan. As previous field measurements show the uniform critical shear stress for cohesive sediment in the top surface layer to be in range of $0.05 \sim 0.15 \mathrm{~Pa}$, it is set to $0.05 \mathrm{~Pa}$. The critical shear stress for noncohesive sediment is calculated from a modified Shields parameter [Yalin and Karahan, 1973]. The critical shear stress in intermediate and deep water (depositional 


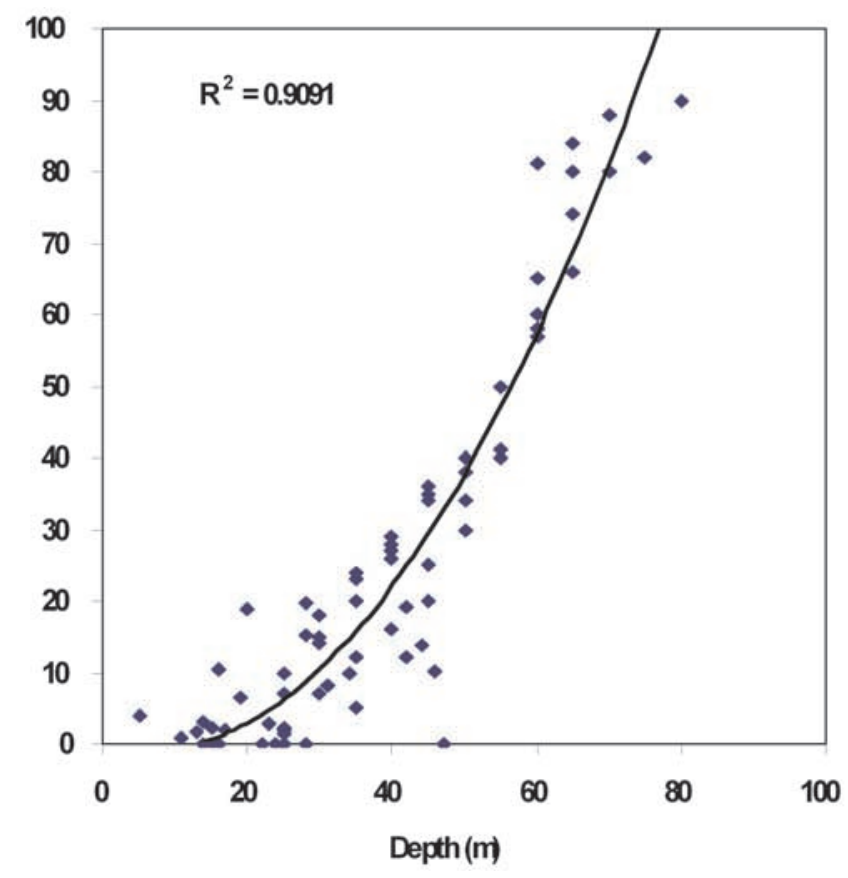

Figure 3. Correlation between fine-grained sediment fraction versus water depth.

regions) must increase with sediment depth as the cohesive sediments are the dominant component subject to consolidation processes. Since the sediments in this area are not eroded at all by wind-generated short waves or currents, we do not need an accurate specification of critical shear stress profiles in the depositional regions.

[26] A further sensitivity analysis using a zerodimensional resuspension model used in the previous study [Lee et al., 2005] at several stations ranging from low to high percentage of fine-grained sediment indicated that the erosion rate constant $\left(\mathrm{M}_{0}\right)$ for cohesive sediment may be correlated to the fine-grained fraction (Figure 4). The resuspension rate constant exponentially decreases with increasing fine-grained fraction. A similar correlation is found in Torfs' [1995] laboratory experiment using a mixture of sand and natural mud. A curve fitting procedure for relating the resuspension rate constant to the finegrained sediment fraction is used to update the erosion rate constant at every time step in the resuspension model.

[27] Spatial distributions of the fine-grained fraction are easily measured but it is extremely difficult to measure fine sediment availability in the coastal region, particularly the total mass of fine-grained sediment $\left(\mathrm{M}_{\mathrm{coh}}=\mathrm{f}_{\mathrm{cs}} \rho_{\mathrm{b}} \Delta \mathrm{z}_{\max } \mathrm{A}_{\mathrm{s}}\right)$ available in the surface bed layer. In the coastal region, fine sediments are mixed and usually confined in a top surface layer whose thickness varies with location and water depth. The availability varies over time, space, and episodic events, depending on the local fraction of fine-grained sediment and the thickness of the maximum active surface layer $\left(\Delta z_{\max }\right)$. Therefore, we assumed that all available finegrained materials in the coastal region were resuspended during the largest resuspension event over the simulation period. The maximum active surface layer $\left(\Delta z_{\max }\right)$ was determined indirectly from the maximum concentration of fine-grained materials over the period $\left(\Delta \mathrm{z}_{\max }=\mathrm{C}_{\max } \cdot \mathrm{h} /\right.$ $\left.\left(\mathrm{f}_{\mathrm{cs}} \rho_{\mathrm{b}}\right)\right)$. The event in 1998 spring was one of the largest events in history and the bed stress in coastal region during this period was extremely high, enough to stir up the entire bed. This maximum active surface layer thickness for finegrained sediment was estimated to be $2.5 \mathrm{~cm}$ in southern Lake Michigan. In the northern coastal region, the thickness was set to $0.5 \mathrm{~cm}$ because the area mainly consists of bedrock or pure sand with a very thin fluffy layer and a very limited cohesive sediment supply from bluffs.

[28] Lateral sediment fluxes are estimated from the Great Lakes shoreline erosion and shoreline type data [Monteith and Sonzogni, 1976; Stewart, 1998] in such a way that the time-dependent loadings are proportional to the local wave energy at the shoreline, i.e.,

$$
F_{L}=F_{L C}+F_{L N}=\left(f_{c s}+f_{n s}\right) L_{c o u n t y}\left(\eta_{w} / \bar{\eta}_{w}\right)^{2}
$$

where $F_{L}$ is the total lateral sediment loading, $F_{L C}$ is the lateral fine-grained sediment loading, $\mathrm{F}_{\mathrm{LN}}$ is the lateral loading of coarse sediment, $\mathrm{f}_{\mathrm{cs}}$ is the fine-grained sediment fraction, $f_{n s}$ is the coarse sediment fraction, $L_{\text {county }}$ is the average county loading per one grid cell, $\eta_{w}$ is the simulated wave height at the shoreline grid cell, and $\bar{\eta}_{w}$ is the averaged wave height at the shoreline grid cell over a year. The sum of the sediment fractions of shoreline materials is not necessarily unity because of armored shorelines in city areas or rocky shorelines in northern Lake Michigan. Tributary loading was also added to the grid cell at each river mouth location. Total lateral loading was dominated by shoreline erosion but it was about $10 \%$ of the sediments resuspended by the largest event in the simulation period. The input parameters for the sediment transport model are summarized in Table 1.

\section{Results and Discussions}

4.1. Hydrodynamics and Bed Shear Stress Distribution [29] The computed circulation patterns are illustrated through the particle tracking method in Figure 5. The figure

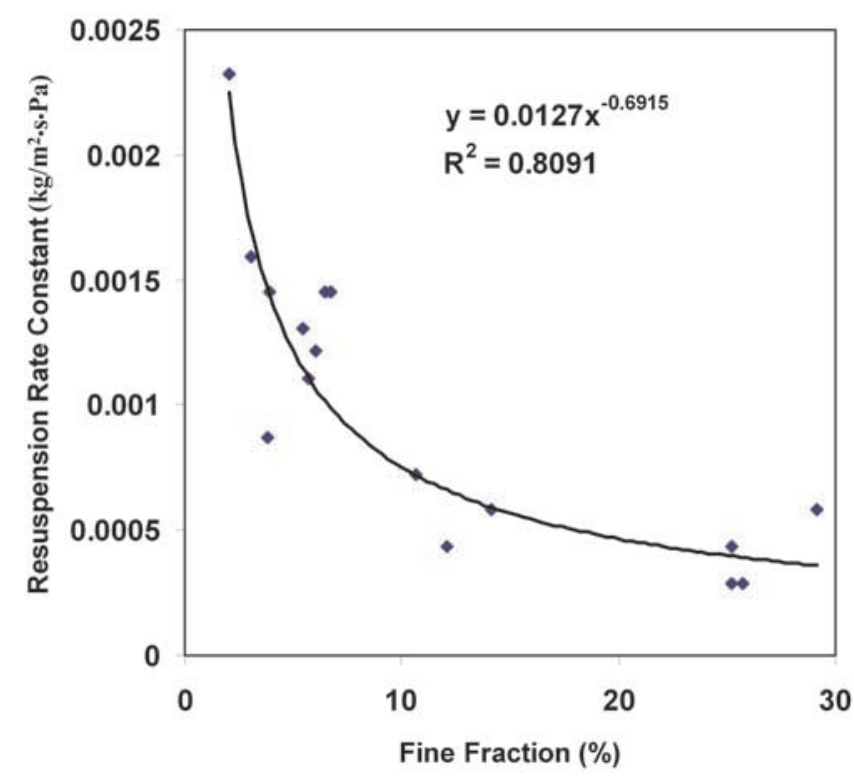

Figure 4. Resuspension rate constant versus fine-grained sediment fraction. 
Table 1. Parameters for Sediment Transport Model

\begin{tabular}{ll}
\hline \multicolumn{1}{c}{ Parameters } & \multicolumn{1}{c}{ Values } \\
\hline $\mathrm{f}_{\mathrm{cs}}$ (fine-grained sediment fraction) & measured \\
$\tau_{\mathrm{c}}$ (critical shear stress for cohesive sediment) & measured $(0.05 \mathrm{~Pa})$ \\
$\mathrm{M}_{0}$ (resuspension rate constant) & estimated depending on $\mathrm{f}_{\mathrm{cs}}$ \\
$\delta_{\mathrm{m} \text {,active }}$ (maximum active layer thickness) & $0.025 \mathrm{~m}$ \\
$\mathrm{~W}_{\mathrm{s}}$ (settling velocity) & calculated \\
$\mathrm{d}_{\mathrm{f}}$ (floc size range) & $0 \sim 20,20 \sim 300,300 \sim 1000 \mu \mathrm{m}$ \\
$\mathrm{d}_{50}$ (mean sand size) & $200 \mu \mathrm{m}$ \\
\hline
\end{tabular}

depicts the trajectories of passive tracer particles that are introduced into the computed depth-averaged velocity field on March 1 and traced through the 30-day computational period. A technique developed by Bennett et al. [1983] and Bennett and Clites [1987] was used to compute the particle trajectories, including a method for interpolating the computed velocity field from the velocity points on the computational grid to the particle locations. Particles are initially located in the center of every third grid cell. To illustrate the cross-isobath transport (offshore transport), tracer particles initially released in cells with depth less than $30 \mathrm{~m}$ are colored orange. To enhance the perception of fluid motion, a bright spot depicts current particle locations at each time step and previous locations of that particle for the last 48 hours are depicted as spots of diminishing intensity. Therefore, the length of 'tail' on each particle indicates the particle's speed and the position indicates a history of the particle's recent locations [Schwab et al., 2000].

[30] Hydrodynamic model results show that the circulation is highly episodic and entirely wind-driven in early spring. A characteristic of the wind-driven circulation in southern Lake Michigan is a pattern consisting of two counter-rotating gyres: a counterclockwise-rotating gyre to the right of the wind direction and a clockwise-rotating gyre to the left [Bennett, 1974; Saylor et al., 1980; Schwab, 1983; Beletsky and Schwab, 2001; Beletsky et al., 2003]. Where the two gyres converge (or diverge) there is a region of offshore transport (or onshore transport) at that point on the shore of the lake. The convergence (or divergence) region changes or disappears depending on the details of the wind field. The simple two gyre systems can be modified by stratification or vorticity in the wind field. The largest currents and maximum vorticity occur in the fall, winter, and early spring when stratification effects are small but wind stresses are strongest. These features are in good agreement with observations [Rao et al., 2002; Beletsky et al., 2003]. Those characteristics are clearly seen during several episodic wind events in March 1998 (Figure 5). The first storm with strong northerly wind $(17 \mathrm{~m} / \mathrm{s})$ peaked on March 9 and generated strong alongshore southerly current that converged near Benton Harbor on the southeastern shore of the lake with southward flow from the western side of the lake. This current system was fully developed for several days after the peak of the wind event. At the convergence zone, a significant offshore mass transport lasted for several days. The second northerly wind event on March 21 also produced two gyres but the counter clockwise-rotating gyre was more prominent than the clockwise-rotating gyre (weakly apparent along the eastern coast) resulting in no significant offshore mass transport. The southerly wind events during March 26-27 caused two gyres which were reversed in circulation sense from the other events with weak onshore transport near Benton Harbor instead of offshore transport.

[31] Results from the bottom boundary layer model show that the spatial distribution of bed shear stress in the southern basin is mainly the result of wind-generated waves and is well correlated to northerly wind events with long fetch distance (Figure 6). A characteristic of wind-generated waves is a short development and attenuation time, quickly responding to wind speed, duration and direction. During the first and second northerly wind events the bed shear stress exceeded $0.2 \mathrm{~Pa}\left(=4 \tau_{\mathrm{c}, \mathrm{cs}}\right)$ over most of the coastal area in the southern basin. During the southerly wind events the bed shear stress exceeded $\tau_{\mathrm{c}}$ only in a limited area along the west and east coasts. Bed shear stress contribution from current was usually less than $10 \%$ but it was significant near the convergence zone in the southeastern basin on March 10 and 11 when the currents were fully developed.

\subsection{Sediment Resuspension and Transport}

[32] For a quantitative comparison of model results with satellite images, suspended fine sediment concentration was converted to light reflectance using a calibration curve constructed from field measurements and SeaWIFS satellite image data in 1999 (Figure 7). The satellite image was corrected geometrically and optically. To consider the sensitivity of satellite observations to particle size distribution (more sensitive to small particles and less sensitive to large particles) we assumed that the upper boundary of data in the calibration plot represented the largest size class and the lower boundary represented the smallest size class. Light reflectance in the model was calculated as a weighted average of that for each size class using the calibration curve.

[33] Figure 8 shows representative snapshots of modeled, fine sediment concentration corresponding to the available SeaWIFS satellite images in Figure 9. Sediment resuspension occurred very quickly, responding to wave-generated bed shear stress exceeding the critical value. The first storm (March 8 10) caused a major resuspension (with about $60 \sim 70 \mathrm{mg} / \mathrm{L}$ of peak concentration at the measurement stations) in the southern coastal region (generally within the $30 \mathrm{~m}$ isobath). Additional significant resuspensions occurred during March 13 14 and March 20 22. The peak concentration was almost coincident with the peak wave height except for the two offshore stations affected by advection, and very fine particles stayed in suspension for several days after the event. The sediment transport model was fairly successful in reproducing both the magnitude and spatial distribution of resuspension. During the first event, the resuspended materials were transported by a large 


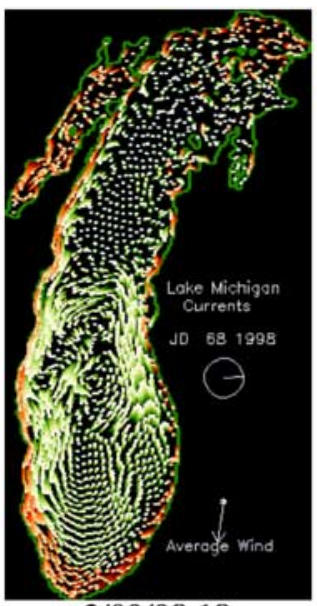

$3 / 09 / 9818 z$

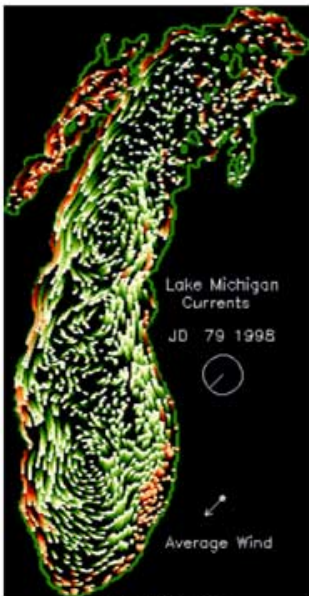

$3 / 20 / 9818 z$

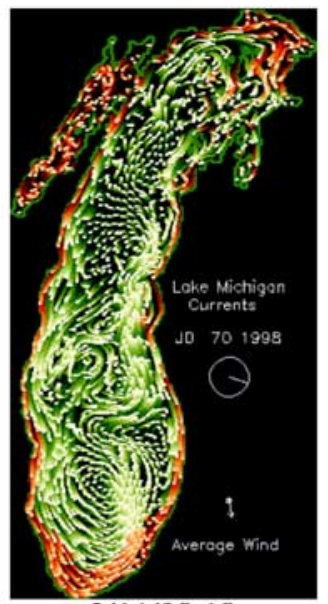

$3 / 11 / 9818 z$

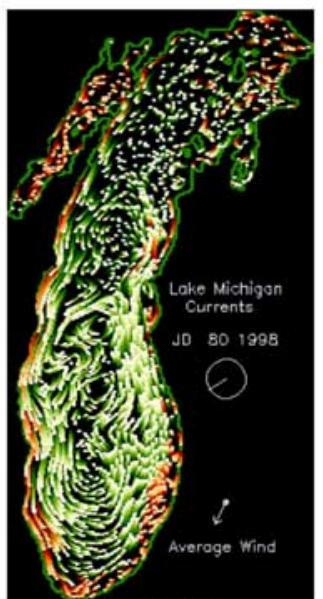

$3 / 21 / 9818 z$

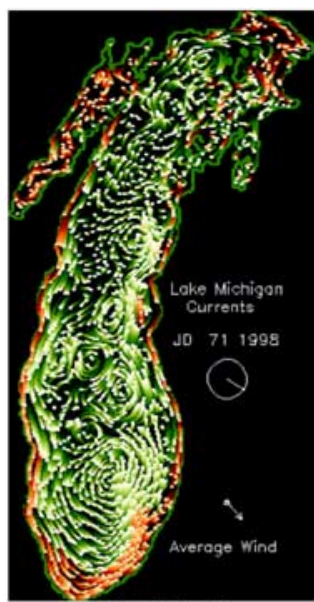

$3 / 12 / 9819 z$

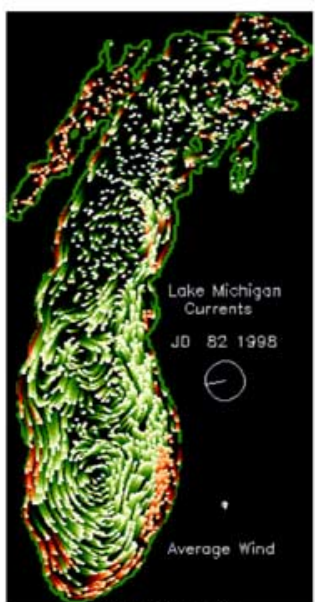

$3 / 23 / 9818 z$

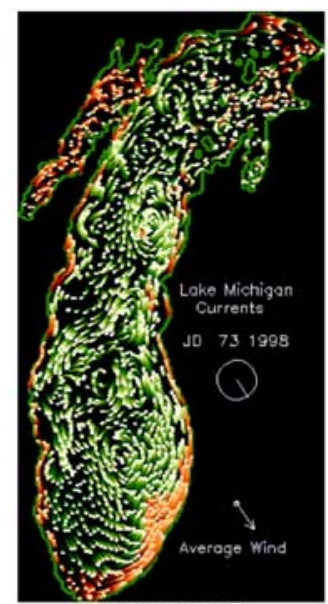

$3 / 14 / 9818 z$

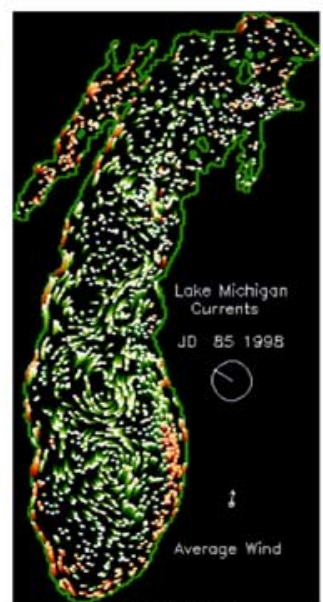

$3 / 26 / 9818 z$

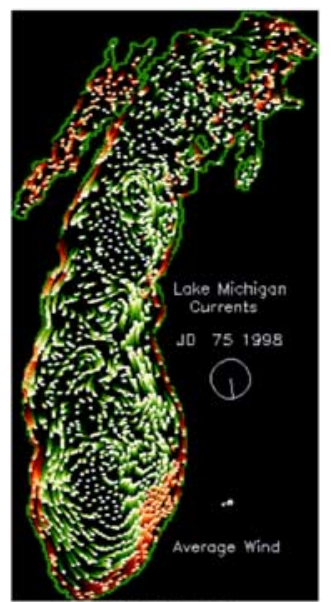

$3 / 16 / 9819 \mathrm{z}$

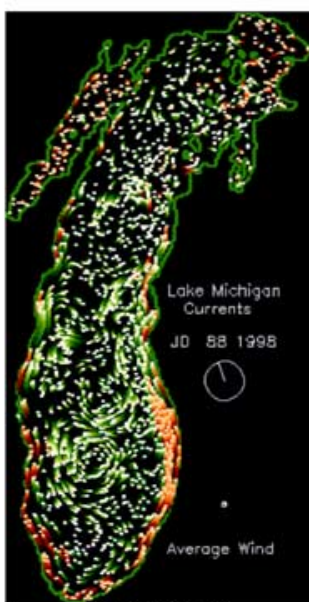

$3 / 29 / 9819 z$

Figure 5. Snapshots of passive particle trajectory representing wind-generated circulations [Schwab et al., 2000].

counterclockwise gyre along the west and southwest coastline and by a small clockwise gyre along the east and southeast coastline (refer to Figure 5). These two plumes converged and transported suspended materials offshore to the southeastern deposition zone. This feature can be clearly seen in the modeled images on March 11 and 12 as well as in the satellite images. The detailed structure of the spiral eddy is not perfectly matched, most likely because of errors in the hydrodynamic prediction. As the wind decreases after the first event, the large counterclockwise gyre becomes prominent while the small clockwise gyre dies out. Following the change of circulation pattern the plume begins to move north along the east coast. Clearer water, which appears to be a remnant of the small clockwise gyre, continually intrudes southward into the plume along east coastline. That feature was also observed by satellite until March 24. As the southerly wind event (March 25 27) approaches, the two counter-rotating gyre system reverses. The clear water intrusion cannot be seen anymore and the plume continually extends to the north along the east coast. The offshore plume also continues to move north and is eventually transported to the central basin along the streamline of the large gyre.
[34] Figure 10 compares model results with ADCP measurements at four stations. Red, blue and black colors indicate the measurements, zero-dimensional (0D), and two-dimensional (2D) model predictions respectively. Herein, a simple zero-dimensional (depth-averaged and no advection) model simulation was also performed to investigate the effect of advection. The zero-dimensional model has exactly same formulation as the $2 \mathrm{D}$ model except for eliminating the advection terms in equation (5). Diurnal variations in the ADCP data are due to vertical migrations of phytoplankton, not sediment resuspension. Overall, the 2D model predicts the four major events well in spite of a time-shifting of peak concentration between model and measurements at the two offshore stations (A2, A5) in the first event and some overprediction by the model on March 12 at the inshore station (A1). The model is also successful in reproducing the relatively uniform concentration (observed from current and previous measurements) across the plume during a large event. The model predictions of peak concentration during the first large event show a relatively small gradient $(40 \sim 65 \mathrm{mg} / \mathrm{L})$ across the plume despite a large variation $(0.35 \sim 2 \mathrm{~Pa})$ of the peak bed shear stresses. Relatively uniform concentration across the plume was also observed from previous field measurements during 


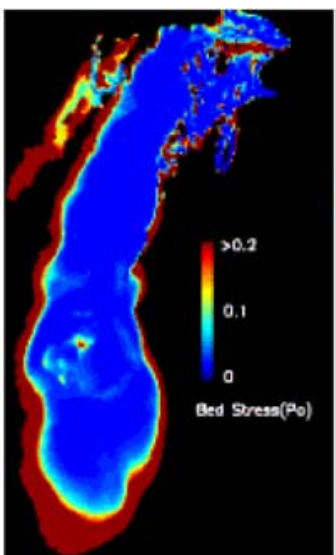

$3 / 09 / 9818 \mathrm{z}$

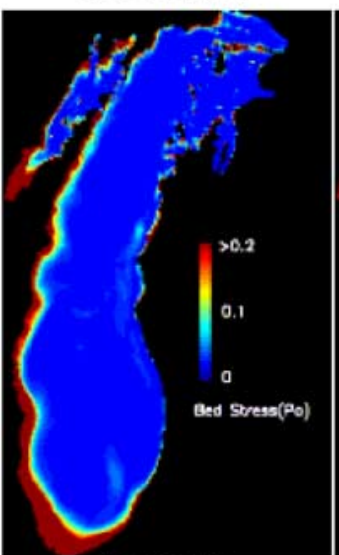

$3 / 20 / 9818 \mathrm{z}$

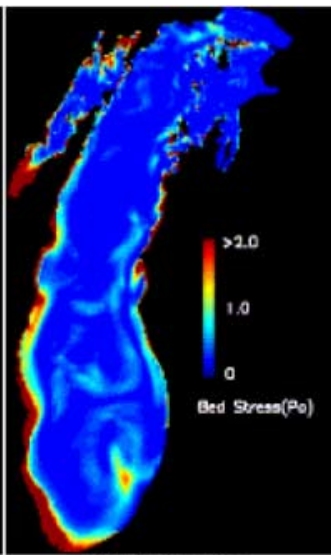

$3 / 11 / 9818 \mathrm{z}$

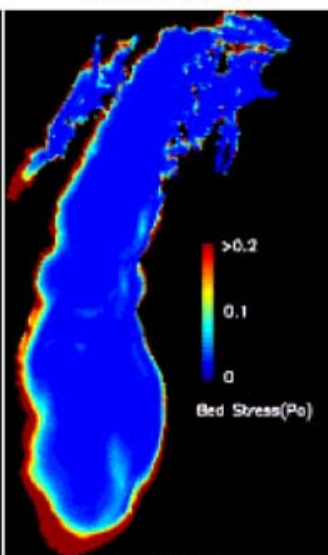

$3 / 21 / 9818 \mathrm{z}$

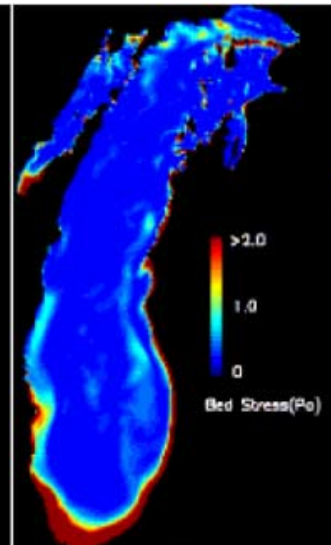

$3 / 12 / 9819_{\mathrm{Z}}$

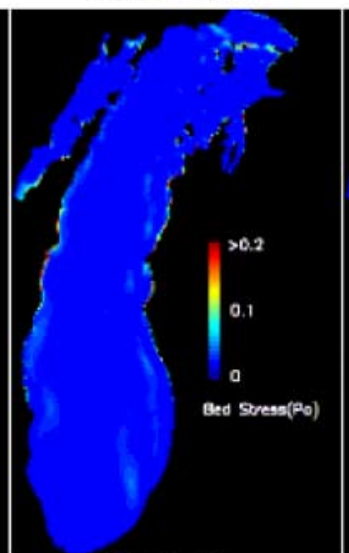

$3 / 23 / 9818 \mathrm{z}$

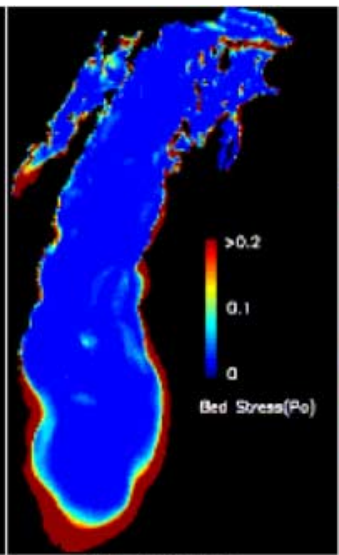

$3 / 4 / 9818 \mathrm{z}$

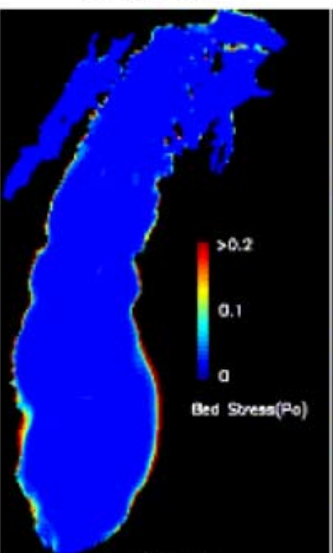

$3 / 26 / 9818 \mathrm{z}$

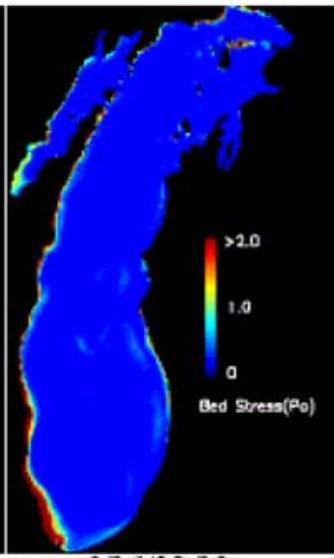

$3 / 16 / 9819 \mathrm{z}$

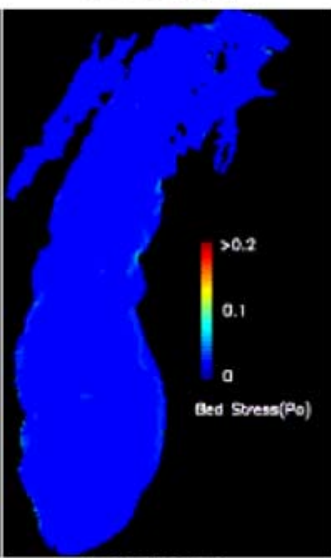

$3 / 29 / 9819 \mathrm{z}$

Figure 6. Snapshots of wave and current bed shear stress distribution.

the EEGLE experiment. One possible reason is that the resuspension rate is proportional to the fine-grained sediment fraction, which tends to be higher at the offshore stations than inshore stations. The time-shifting errors, at two offshore stations around March 11, may be attributed to a delayed advection effect. The stations were located near the plume edge (with high gradient of concentration) where significant offshore transport occurred during the first event. Therefore, it is difficult to accurately predict the concentration without a perfect simulation of the timing and scale of

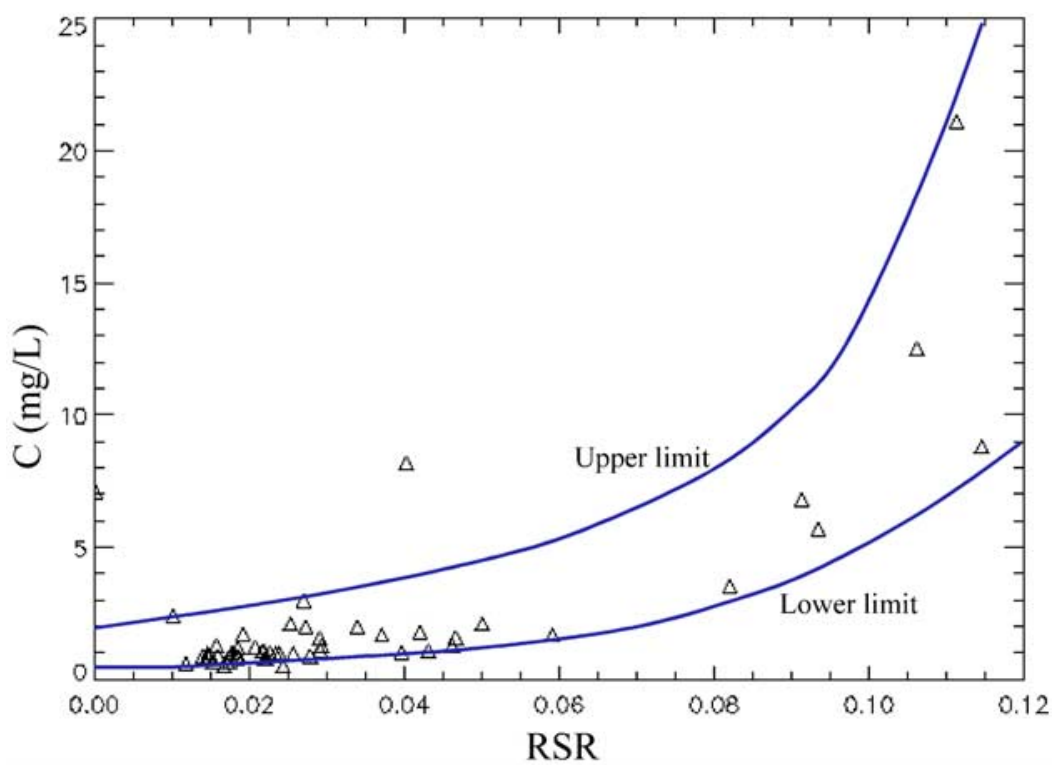

Figure 7. Suspended particle concentration versus SeaWIFS satellite light reflectance. 


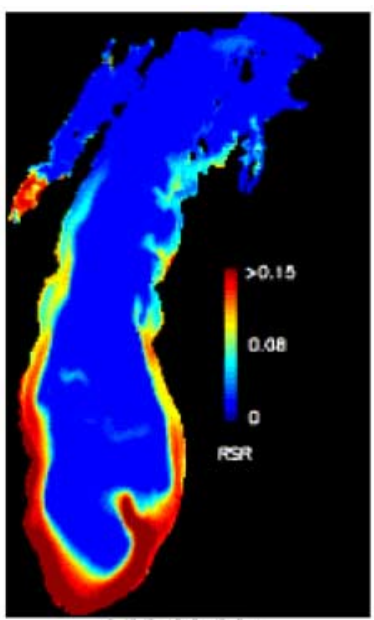

$3 / 11 / 9818 \mathrm{z}$

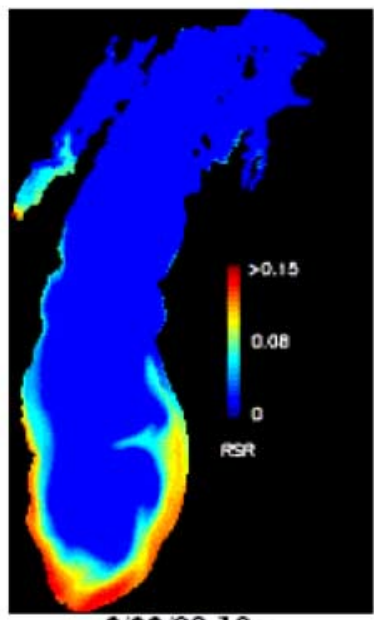

$3 / 23 / 9818 \mathrm{z}$

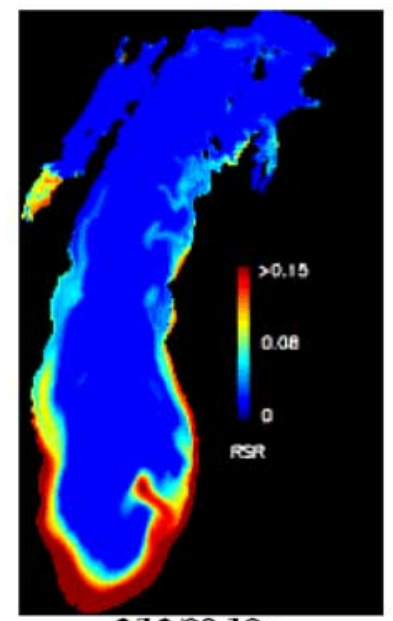

$3 / 12 / 9819 \mathrm{z}$

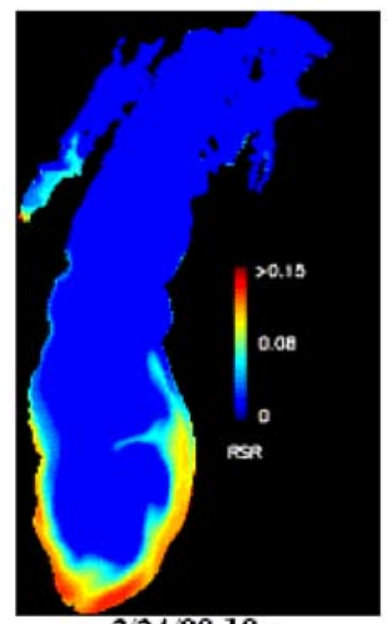

$3 / 24 / 9818 \mathrm{z}$

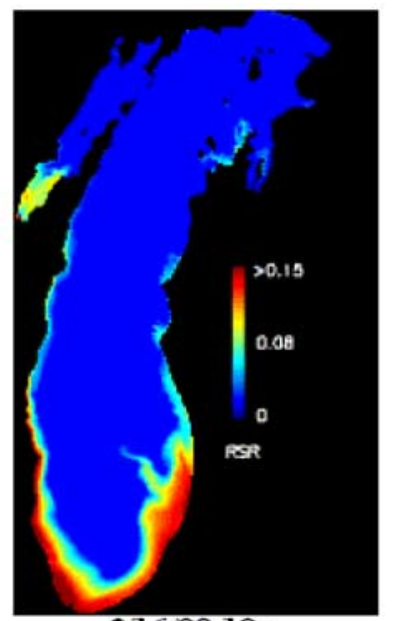

$3 / 16 / 9810 \mathrm{z}$

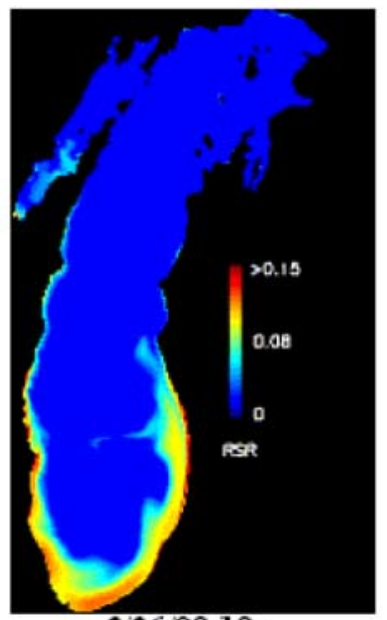

$3 / 26 / 9818 \mathrm{z}$

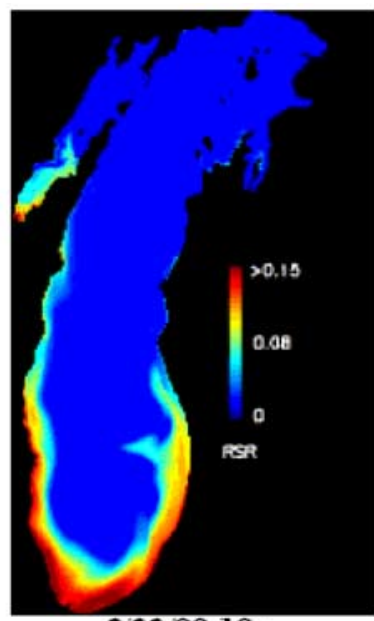

$3 / 22 / 9818 \mathrm{z}$

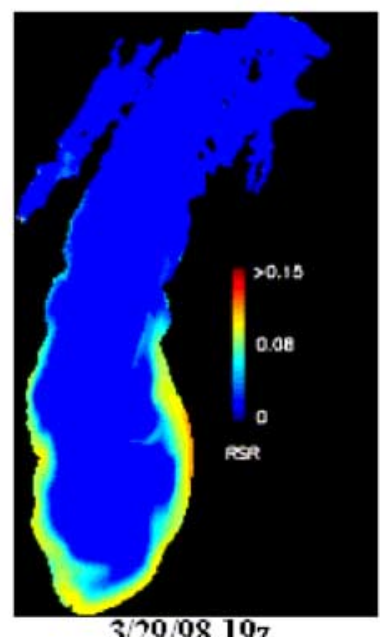

$3 / 29 / 9819 \mathrm{z}$

Figure 8. Model images of fine-grained sediment resuspension scaled to SeaWIFS images in Figure 9.

advection process. To identify the cause of the time-shifting error, the local budget of sediment fluxes (resuspension, deposition, and advection) was computed at each station for the $2 \mathrm{D}$ model in Figure 11 along with the time-series prediction (blue line) for the $0 \mathrm{D}$ model (no advection and depth-averaged) in Figure 10. During the first event, the 0D model shows two distinct peaks at A2 coincident with peaks in the local bed stresses but significantly underpredicted in magnitude while the 2D model shows only one peak shifted back about half day at A1 and a day at A2 relative to $1 \mathrm{D}$, indicating advection. The budget plots of fluxes clearly show that the advection is responsible for the time-shifted peak at A2 and A5 (Figure 11). Errors in the hydrodynamic model [Beletsky et al., 2003] are the most likely cause. During the second northerly wind event (March 19 21), resuspension was observed only at the inshore stations. The models agreed with measurements very well but the $0 \mathrm{D}$ model overpredicted the concentration at A1. The differences between the $0 \mathrm{D}$ and 2D model results come from advection and possibly bed armoring. The $0 \mathrm{D}$ model assumes no advection. Therefore, the active bed layer thickness limiting the amount of available fine-grained sediment depends only on bed shear stress. The $2 \mathrm{D}$ model allows strengthening or weakening the bed armoring effect due to advecting sand particles. For example, continuous bed erosion by negative advection allows the deeper penetration of flow turbulence. Net erosion of the sand bed exposed the fine-grained sediment particles hiding deeper in the bed layer to the resuspension.

[35] The model reflectance tended to be higher than the observed values during the first event on March 11 and lower than observations after the last event on March 29. The difference may be for several reasons: (1) uncertainty in the calibration curve, (2) uncertainty in the initial bed property distribution, and (3) limitations of the sediment model. All of them are possible, and it is difficult to sort out the most important individual effect. However, the comparison of model with ADCP measurements (Figure 10) at four measurement stations (A1, A2, A3, A4) suggests that the first reason might be the main source of error. The variance of ADCP measurement was roughly estimated to be $\pm 3 \mathrm{mg} / \mathrm{L}$ while the variance of satellite data was estimated to be $\pm 5 \sim 10 \mathrm{mg} / \mathrm{L}$. Theoretically, the acoustical back-scattering signal falls off significantly outside or near the lower limit of the range. The appropriate measurement range of $600 \mathrm{KHz} \mathrm{ADCP}$ is $8 \sim 800 \mu \mathrm{m}$ corresponding to particle circumference/wavelength $\left(\pi \mathrm{d} / \mathrm{k}_{\mathrm{a}}=0.01 \sim 1.0\right)$, covering the size range of most suspended particles. The 


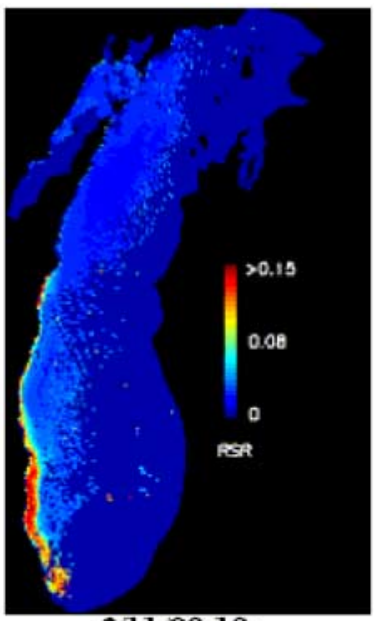

$3 / 11 / 9818 z$

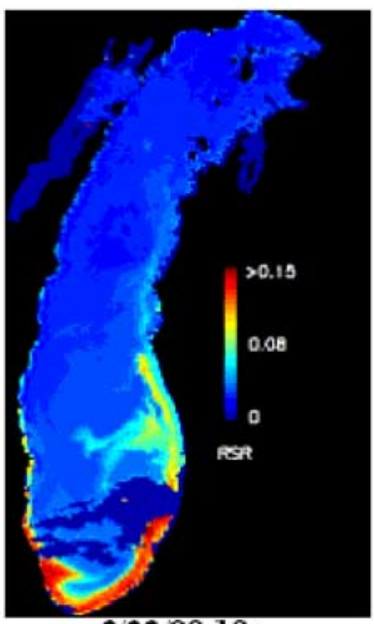

$3 / 23 / 9818 \mathrm{z}$

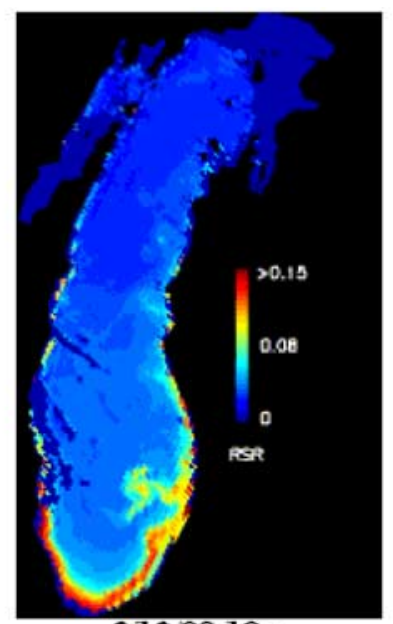

$3 / 12 / 9819 \mathrm{z}$

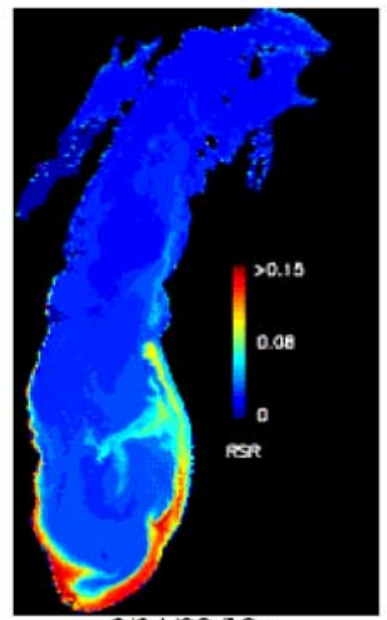

$3 / 24 / 9818 \mathrm{z}$

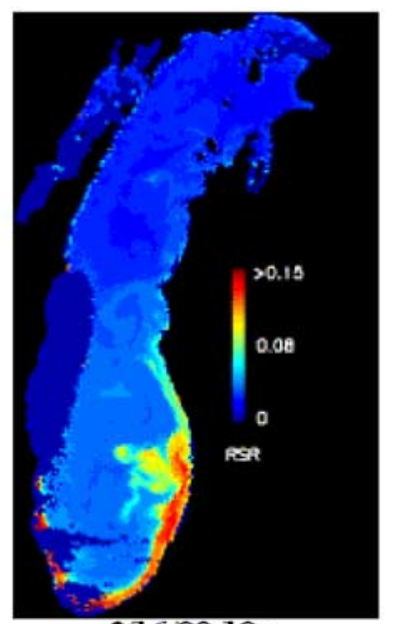

$3 / 16 / 9819 \mathrm{z}$

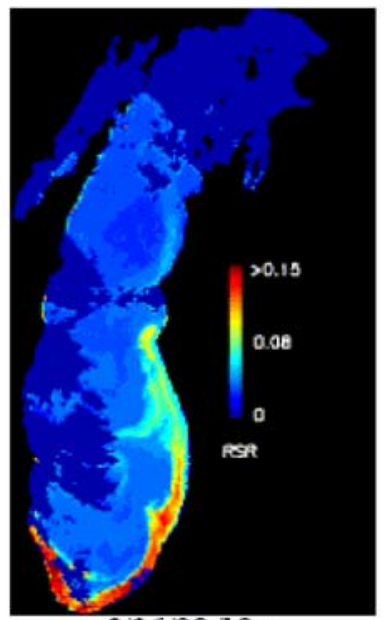

$3 / 26 / 9818 z$

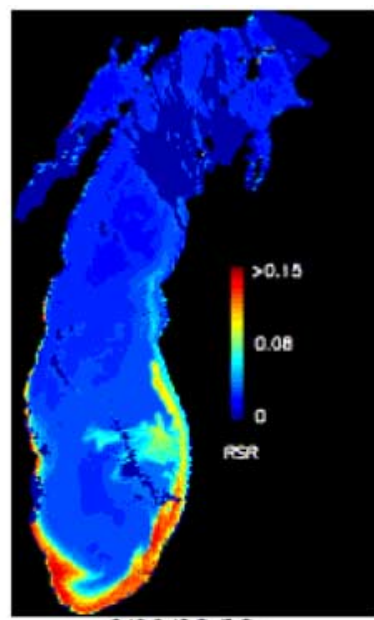

$3 / 22 / 9818 \mathrm{z}$

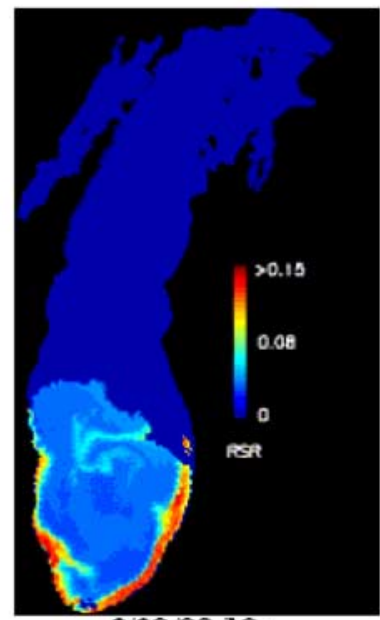

$3 / 29 / 9819 \mathrm{z}$

Figure 9. SeaWIFS images of light reflectance from resuspension plume.

ADCP measurements are probably less uncertain than satellite observations with their inherent large error sources (high sensitivity to particle size and concentration, cloud cover, light intensity and angle, geometrical error), when compared to nearby transmission meter and water intake data. For instance, the reflectance from satellite observation varies little during March while the ADCP measurements show a large variation of suspended sediment concentration- compare ADCP measurements with the two satellite images on March 12 and 29. The reason may be attributed to the nonlinear relation of light reflectance to concentration and size distribution. Satellite measurement of light reflectance is much more sensitive to very small particles, but much less sensitive to high concentration exceeding a certain range $(10 \sim 100 \mathrm{mg} / \mathrm{L})$ [Gordon and Morel, 1983; $\mathrm{Li}$ and $\mathrm{Li}, 2000]$. Therefore, the reflectance value may underestimate the high concentrations due to large particles typical during the large resuspension events. On the contrary, it may overestimate concentrations for very small particles staying in the water for several days after the event. Those effects result in less variation of reflectance over time. Despite the large uncertainty in reflectance $( \pm 0.01$ at $20 \mathrm{mg} / \mathrm{L})$, the satellite observations are very useful to compare with spatial distribution patterns in the model results as well as to compare concentration estimated within the uncertainty range.

\subsection{Settling Flux and Deposition}

[36] The model settling fluxes of fine-grained materials were compared to measurements using cylindrical sediment traps at four stations, T12, T15, T20, and T24 (Figure 12). As the traps were deployed at middepth, the settling flux of suspended sand was negligible. The fluxes were integrated over three 9-days periods (P1-March 4 12, P2-March 13 21, and P3-March 22 30), which include three major episodic events. Generally, the model prediction tends to be higher than measurements except at station T24. Considering the deployment depth of the sediment trap (which cannot capture all settling materials) and some shaking effect inside the sediment trap during strong wave and current action, the model estimations $\left(=\mathrm{w}_{\mathrm{s}} \mathrm{C}\right)$ are in reasonable agreement with trap data. Model and measurement show the largest settling flux (P1) after the first event. Fluxes are lower for subsequent events. The settling fluxes at the nearshore station T15 were consistently higher than the other offshore stations (T12, T20, T24) located near or outside the plume edge most of the time. A significant overestimation during the first integration period (P1) at T24 is probably due to an overestimation of the advection 

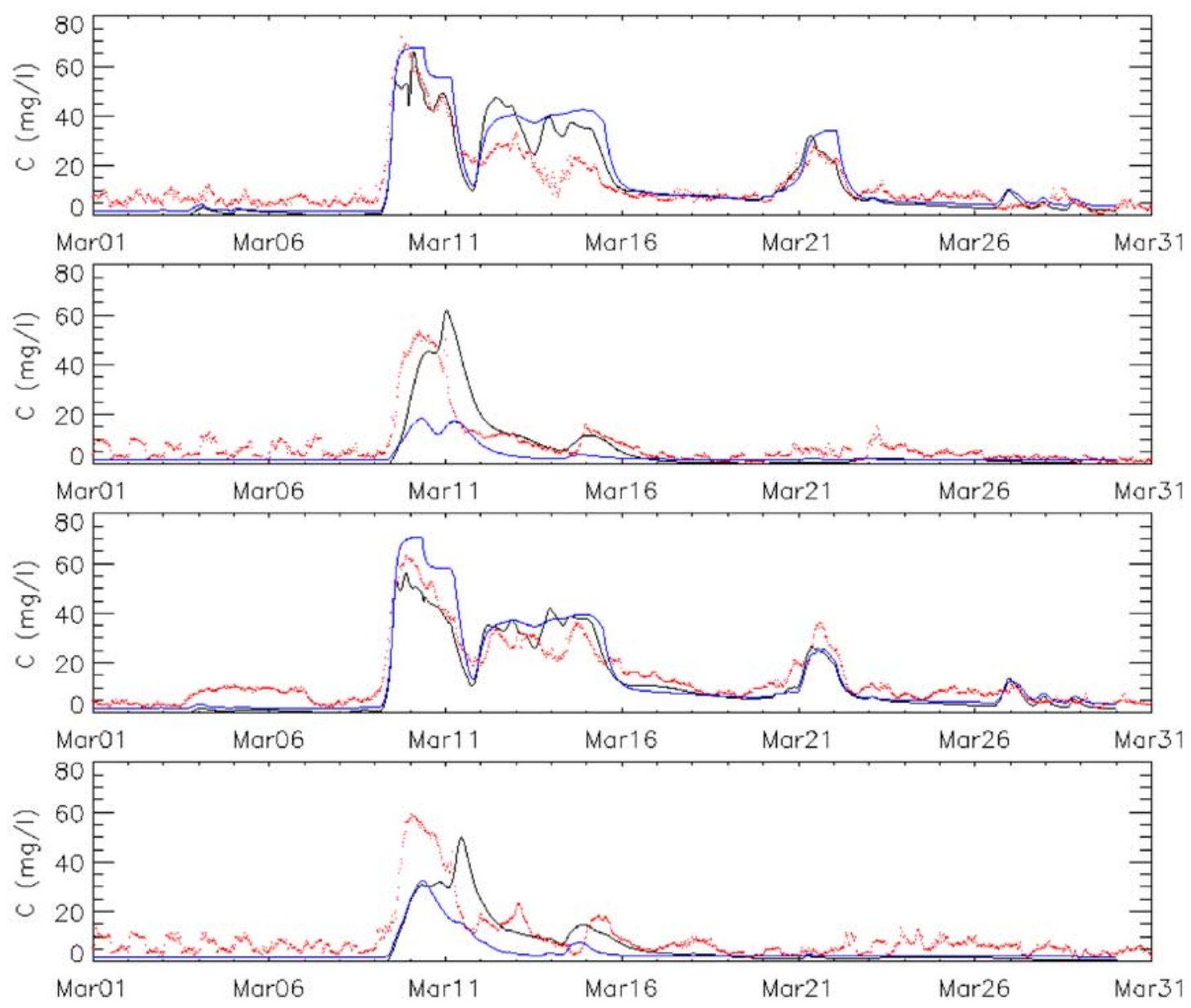

Figure 10. Time series of fine sediment concentration. Black-2D model, blue- zero-dimensional model, red-ADCP measurements. Stations A1, A2, A4, and A5 from upper to lower plot.

effect by the model. The effect is obvious in the comparison of model and satellite reflectance images on March 12. The model settling flux at the center of the southern basin (T12) is not measurable $\left(<0.001 \mathrm{~g} / \mathrm{m}^{2} /\right.$ day $)$ while the measurement shows a nonnegligible settling flux. The numerical model reproduces the spiral feature in the resuspension plume observed by satellite, but the nonnegligible flux in the center of the basin indicates that the model underpredicts the concentration of very fine lingering particles transported to the center of the basin by the large-scale spiral eddy.

[37] The computed net sedimentation rate over a month was compared to the recently measured sedimentation rate averaged over last 30 years for the Lake Michigan Mass Balance Study. The left panel of Figure 13 shows the highly detailed map of modern sediment accumulation rate developed by Eadie and Robbins [2005]. A radiotracer technique using ${ }^{137} \mathrm{Cs}$ and naturally occurring ${ }^{210} \mathrm{~Pb}$ was applied to measure the accumulation rate over hundreds of sampling locations. It reveals preferential accumulation of sediments on the eastern side of the lake despite a predominance of particle sources on the western side. The total amount of accumulated sediment in the southern basin was estimated to be $4.05 \times 10^{9} \mathrm{~kg} / \mathrm{yr}$. The model successfully reproduces this measured sedimentation pattern. The right panel of Figure 13 shows the net deposition pattern on March 31 .
It reproduces the hot spot area along the southeastern side of the lake where deposited materials originated mostly from the western side of the lake. The largest erosion (negative accumulation) occurs along the shores in the southwestern and southeastern part of the lake (indicated by white color). These resuspension areas correspond to areas where the wave-induced bed stress distribution exceeds the critical value for resuspension. In the hot spot area on the $50 \mathrm{~m}$ isobath northwest of Benton Harbor, the computed and measured sedimentation rates are in range of $0.2 \sim 0.3 \mathrm{~g} / \mathrm{cm}^{2}$ per month and year respectively. The total amount of accumulated sediment per month estimated by the model is also close to the measurement value per year. For the following reasons, we feel that the sedimentation rate computed by the model is quantitatively comparable to the measurements despite the fact that a short-term model run is being compared to a yearly averaged long-term sedimentation map. First, the episodic event during March 1998 was the largest in recent history in terms of plume size and concentration. Second, a significant resuspension event usually occurs only during winter and spring times (November through March) when the lake is well mixed and dominated by northerly wind. The satellite observations (NOAA AVHRR) during 1996 through 2002 showed that a series of significant resuspension events occurred about two 

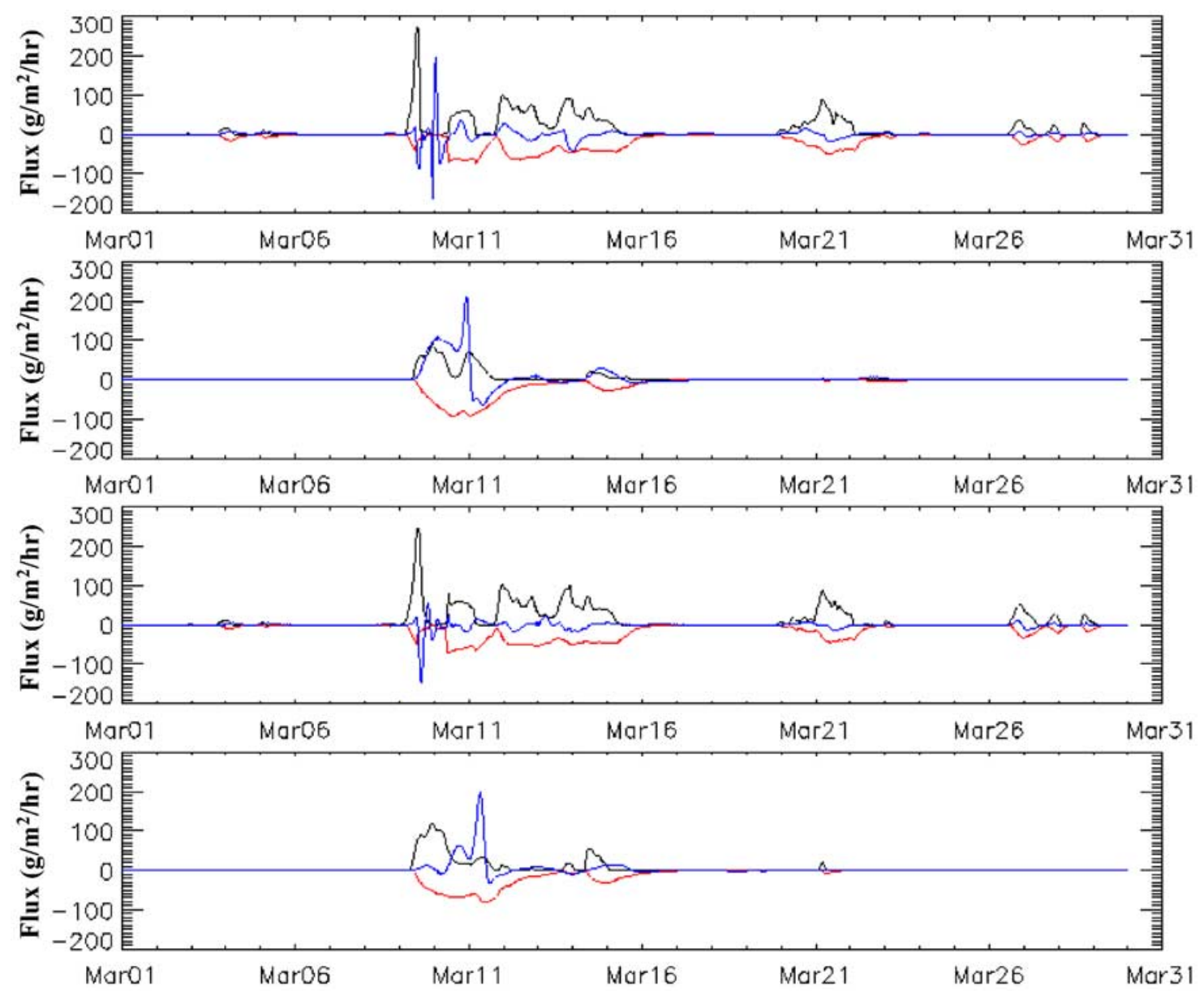

Figure 11. Local budget of resuspension (black), settling (red), and advection (blue) fluxes. Stations A1, A2, A4, and A5 from upper to lower plot.

times per year averagely. Therefore, it may be concluded that the events during March 1998 were strong enough to resuspend and transport an amount of material equivalent to the averaged annual resuspension and sedimentation observed by the field measurements.

[38] A quite significant area of sedimentation (predicted by the model) in the near-center of southern basin (on $100 \mathrm{~m}$ isobath line) is attributed to an erroneous advection effect during March 10 11 as explained in the previous section. Actually, the current-induced bed shear stress was overestimated in the southeastern offshore region where two gyres converged and generated a strong offshore current, causing a significant false resuspension in this area clearly represented by the white color.

[39] Other observed hot spots along the eastern coast are not prominent in the simulated sedimentation map. We should note that the measurement reflects the 30-years average effects of different circulation patterns caused by numerous episodic wind events. The major deposition area is determined primarily by the location of significant offshore transport events. In turn, the location of offshore transport events is controlled by the evolution of two counter-rotating gyres largely depending on the lake circulation climatology [Schwab and Beletsky, 2003]. To better reproduce the measured sedimentation pattern, the long-

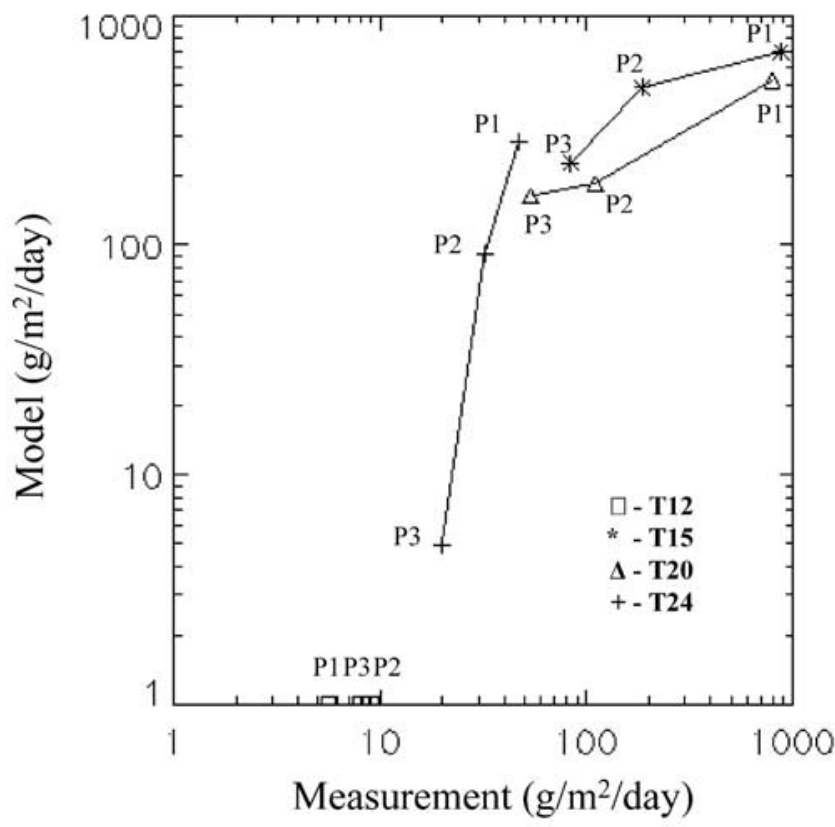

Figure 12. Settling fluxes of suspended sediments. Model versus trap measurements at stations $\mathrm{T} 12, \mathrm{~T} 15, \mathrm{~T} 20$, and $\mathrm{T} 24$. 

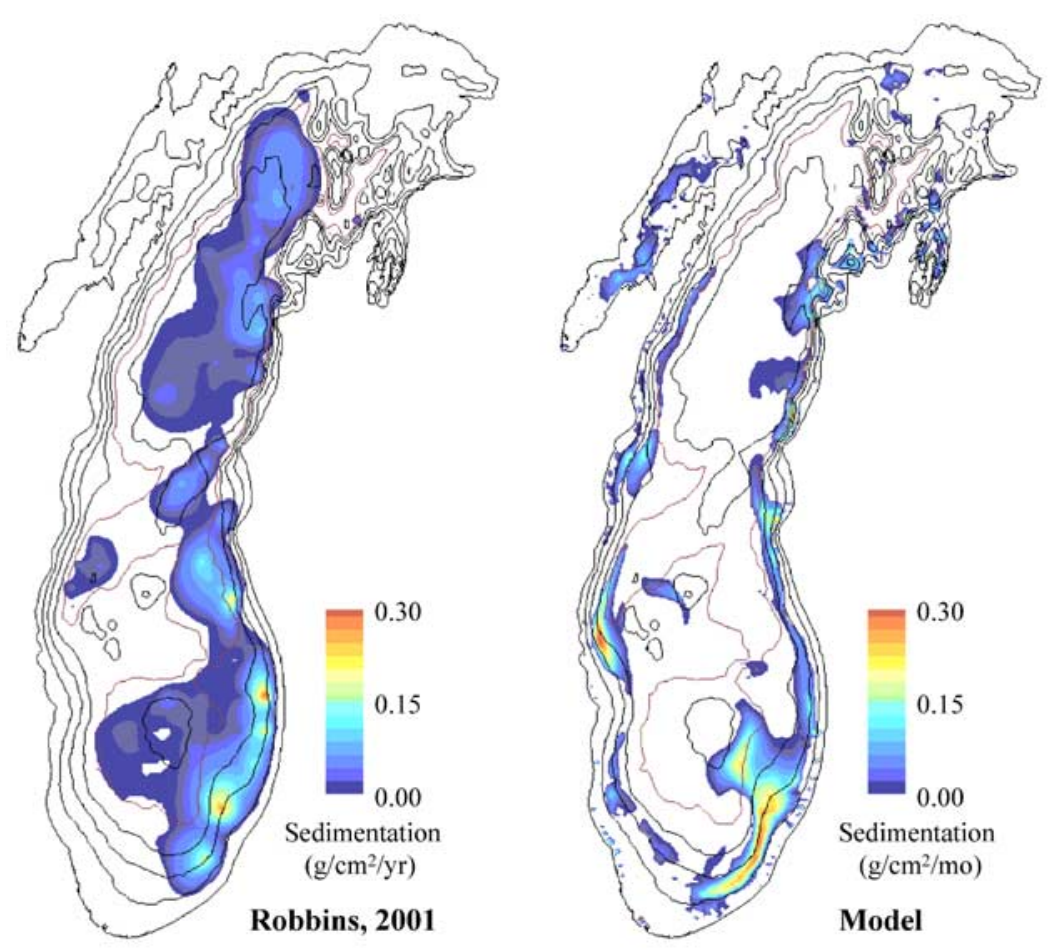

Figure 13. Net sedimentation rate measured by Robbins and calculated from model. Measurement represents 30-year average values. White color (negative value) in model represents erosion.

term effects of circulation climatology should be also considered as well as a better description of hydrodynamics.

\section{Summary and Conclusions}

[40] A two-dimensional sediment transport model was developed and applied to study the sediment resuspension, transport and deposition in southern Lake Michigan. An important feature of the model is the capability to deal with mixed sediment effects more realistically by considering fine sediment fraction, bed armoring, floc size distribution, and sediment availability. Important resuspension parameters were estimated from field or laboratory measurements. Model results were verified with field measurements and compared to SeaWIFS satellite images.

[41] The model reproduced the resuspension plume in March 1998 and recently measured sedimentation rates reasonably well. An analysis of the results shows the particular roles of waves, circulation, and sediment properties in controlling resuspension, transport and deposition in the lake. Waves and sediment bed properties are mainly responsible for sediment resuspension. The location of the resuspension plume generally overlapped the location where the bed shear stress distribution exceeded the critical shear stress. Sediment properties (such as critical shear stress, fine sediment fraction, and sediment availability) determined the concentration distribution and width of the resuspension plume for a given set of wave conditions. Circulation patterns and the settling velocity of fine sediments controlled the transport and deposition. The model showed that the main physical mechanism of offshore sediment transport occurring around the southeastern basin is the two counter-rotating gyre systems caused by a strong northerly wind event. The exact location of offshore transport by these gyre systems changes with episodic wind events, which results in different locations of maximum offshore mass transport. The long-term averaged sedimentation pattern may be the result of the accumulated climatology of these two gyre systems. The settling velocity spectrum is also important in controlling sedimentation, as deposition location is a function of advection and settling velocity. In our model the settling velocity was not a calibration parameter but a calculated value from a physically based formula.

[42] There are some limitations yet to overcome in future study. The hydrodynamics and sediment dynamics such as flocculation, need some improvements to better depict the detailed features of the spiral eddy that are important for offshore transport. More accurate estimates of sediment properties, especially the distribution of the fine-grained fraction with sediment depth, are needed for a better description of initial conditions in the coastal region. For long-term simulation, lateral sediment flux from bluff erosion should be more properly described, and mixing and redistribution processes of fresh materials from coastal erosion should be identified and implemented into the integrated model system.

\section{Appendix A}

[43] Consider the approximation to the sediment advection-diffusion equation for horizontally uniform distribution. The governing equation is reduced to

$$
\frac{\partial(H C)}{\partial t}=\frac{\partial}{\partial z}\left(\frac{K_{v}}{H} \frac{\partial C}{\partial z}+w_{s} H C\right)
$$


Integrating (A1) over the water depth

$$
\frac{\partial(H \bar{C})}{\partial t}=J_{0}-J_{1}
$$

where $\mathrm{J}_{0}$ is the net sediment flux at bottom boundary and $\mathrm{J}_{1}$ is the net sediment flux at water surface boundary which is assumed to be negligible.

[44] Subtracting (A2) from (A1) gives

$$
\frac{\partial\left(H C^{\prime}\right)}{\partial t}=\frac{\partial}{\partial z}\left(\frac{K_{v}}{H} \frac{\partial C}{\partial z}+w_{s} C\right)-J_{0}
$$

Assuming that $\partial_{t}\left(\mathrm{HC}^{\prime}\right)<\partial_{t}(\mathrm{H} \bar{C})$, the equation (A3) is approximated by

$$
\frac{\partial}{\partial z}\left(\frac{K_{v}}{H} \frac{\partial C}{\partial z}+w_{s} C\right)=J_{0}
$$

Integrating (A4) once over z

$$
\frac{K_{v}}{H} \frac{\partial C}{\partial z}+w_{s} C=J_{0}(z-1)
$$

By assuming the turbulent diffusivity, $\mathrm{K}_{\mathrm{v}} / \mathrm{H}=\mathrm{u}^{*} \kappa \mathrm{z}$, and equilibrium conditions $\left(\mathrm{C}=\mathrm{C}_{\mathrm{eq}}\right.$ and $\left.\mathrm{J}_{0}=0\right)$ at $\mathrm{z}=\mathrm{z}_{\mathrm{eq}}$, the solution of the first order differential equation (A5) is given

$$
C=\left(\frac{z_{e q}}{z}\right)^{R} C_{e q}-\left(1-\frac{R z}{1+R}\right) \frac{J_{0}}{w_{s}}
$$

where Rouse number, $\mathrm{R}=\mathrm{w}_{\mathrm{s}} / \mathrm{u}^{*} \kappa$

[45] For sand under nonequilibrium conditions, the net flux is given as

$$
J_{0}=w_{s}\left(\frac{1+R}{1+R\left(1-z_{e q}\right)}\right)\left(C_{e q}-C_{n e}\right)
$$

where $\mathrm{C}_{\mathrm{ne}}$ is the actual concentration at the reference equilibrium level. To express (A7) in terms of the depth averaged sediment concentration $(\bar{C})$, the integration of (A7) over the water depth gives

$$
J_{0}=w_{s}\left(\frac{2(1+R)}{2+R\left(1-z_{e q}\right)}\right)\left(\bar{C}_{e q}-\bar{C}_{n e}\right)
$$

where

$$
\begin{aligned}
& \bar{C}_{e q}=\frac{\ln \left(z_{e q}^{-1}\right)}{\left(z_{e q}^{-1}-1\right)} C_{e q}, R=1 \\
& \bar{C}_{e q}=\frac{\left(z_{e q}^{R-1}-1\right)}{(1-R)\left(z_{e q}^{-1}-1\right)} C_{e q}, R \neq 1
\end{aligned}
$$

The equilibrium concentration for average sand size class at reference level is expressed by Smith and McLean's [1977] formula as follows:

$$
C_{e q}=\rho_{s} \frac{0.65 \gamma_{0} T}{1+\gamma_{0} T}, \quad T=\frac{\tau_{b}-\tau_{c}}{\tau_{c}} \quad, \text { when } \tau_{\mathrm{b}}>\tau_{\mathrm{c}}
$$

where $\gamma_{0}$ is a constant equal to $2.4 \times 10^{-3}$.
[46] Equation (A8) is applied for the arbitrary number of sand size class $\left(\mathrm{n}_{\mathrm{s}}\right)$ as follows:

$$
J_{0}=F_{R}-F_{D}=\left(1-f_{c s}\right) \sum_{j=1}^{n_{s}} w_{s, j} f\left(R, z_{r}\right)\left[f_{s, j} \bar{C}_{e q} \bar{C}_{j}\right]
$$

where $f_{c s}$ is the fraction of fine-grained sediments in bed, $n_{s}$ is the number of sand size classes, $\mathrm{f}\left(\mathrm{R}, \mathrm{z}_{\mathrm{r}}\right)=2(1+\mathrm{R}) /(2+$ $\left.\mathrm{R}\left(1-\mathrm{z}_{\text {eq }}\right)\right)$ with $\mathrm{z}_{\mathrm{r}}=\mathrm{z}_{\mathrm{eq}}, \bar{C}_{j}$ is the depth average concentration for each sand size class, $\mathrm{f}_{\mathrm{s}, \mathrm{j}}$ is the fraction of each sand size class $\left(\sum^{n_{s}} f_{s, j}=1\right)$.

[47] For fine-grained iseddiments, the deposition flux is given as

$$
F_{D}=\left(\begin{array}{ll}
w_{s} C_{d}\left(\frac{\tau_{c d}-\tau_{b}}{\tau_{c d}}\right)=w_{s} P_{d} C_{d} & \tau_{b}<\tau_{c d} \\
0 & \tau_{b}>\tau_{c d}
\end{array}\right.
$$

where $C_{d}$ is the fine-grained sediment concentration at deposition level $\left(\mathrm{z}_{\mathrm{d}}\right), \tau_{\mathrm{cd}}$ is the critical stress for deposition which depends on floc properties. Inserting (A12) into the solution of differential equation (A5) and evaluating the integration constant at the deposition level, we can get

$$
C=\left(1-\frac{R z}{(1+R)}\right) P_{d} C_{d}+\left(1-\left(1-\frac{R z_{d}}{1+R}\right) P_{d}\right) C_{d} \frac{z_{d}^{R}}{z^{R}}
$$

Integrating (A13) over the water depth, we can get

$$
\begin{aligned}
C_{d}= & \left(\left(\frac{2+R\left(1-z_{d}\right)}{2(1+R)}\right) P_{d}+\frac{\ln \left(z_{d}^{-1}\right)}{\left(z_{d}^{-1}-1\right)}\right. \\
& \left.\cdot\left(1-\left(\frac{1+R\left(1-z_{d}\right)}{(1+R)}\right) P_{d}\right)\right)^{-1} \bar{C}, \quad R=1 \\
C_{d}= & \left(\left(\frac{2+R\left(1-z_{d}\right)}{2(1+R)}\right) P_{d}+\frac{\left(z_{d}^{R-1}-1\right)}{(1-R)\left(z_{d}^{-1}-1\right)}\right. \\
& \left.\cdot\left(1-\left(1-\frac{R z_{d}}{(1+R)}\right) P_{d}\right)\right)^{-1} \bar{C}, \quad R \neq 1
\end{aligned}
$$

If the above derivations are applied to the resuspension and deposition flux formula for the arbitrary numbers of floc size class, the net flux gives

$$
J_{0}=F_{R}-F_{D}=\sum_{i=1}^{n_{c}}\left(f_{f, i} f_{c s} M_{0}\left(\tau_{b}-\tau_{c}\right)-w_{s, i} g\left(R, z_{d}\right) \bar{C}_{i} P_{d, i}\right)
$$

where $g\left(R, z_{d}\right)$ is the converting function in (A14) and (A15) that converts the depth averaged concentration to the concentration at the deposition level, $\bar{C}_{i}$ is the depth average concentration for each floc size class, $\mathrm{f}_{\mathrm{f}, \mathrm{i}}$ is the fraction of each floc size class in water column, and $f_{c s}$ is the fraction of fine-grained sediments in bed. 
[48] Acknowledgments. The authors are indebted to J. A. Robbins and B. J. Eadie for providing sediment data and their helpful comments. The authors also would like to thank G. Miller and M. McCormick for providing ADCP data and their assistance in interpreting the data. This work was funded through the Great Lakes Environmental Research Laboratory, NOAA (contribution 1404)

\section{References}

Beletsky, D., and D. J. Schwab (2001), Modeling circulation and thermal structure in Lake Michigan: Annual cycle and interannual variability, J. Geophys. Res., 106(C9), 19,745-19,771.

Beletsky, D., D. J. Schwab, P. J. Roebber, M. J. McCormick, G. S. Miller, and J. H. Saylor (2003), Modeling wind-driven circulation during the March 1998 sediment resuspension event in Lake Michigan, J. Geophys. Res., 108(C2), 3038, doi:10.1029/2001JC001159.

Bennett, J. R. (1974), On the dynamics of wind-driven lake currents, J. Phys. Oceanogr., 4, 400-414.

Bennett, J. R., and A. H. Clites (1987), Accuracy of trajectory calculation in a finite-difference circulation model, J. Comput. Phys., 68, 272-282.

Bennett, J. R., A. H. Clites, and D. J. Schwab (1983), A two-dimensional lake circulation modeling system: programs to compute particle trajectories and the motion of dissolved substances, NOAA Tech. Memo. ERL GLERL-46, 51 pp., Great Lakes Environ. Res. Lab., Natl. Oceanic and Atmos. Admin., Ann Arbor, Mich.

Blumberg, A. F., and G. L. Mellor (1987), A description of a threedimensional coastal ocean circulation model, in Three-Dimensional Coastal Ocean Models, Coastal Estuarine Stud., vol. 5, edited by N. S. Heaps, pp. 1-16, AGU, Washington, D. C.

Brooks, A. S., and D. N. Edgington (1994), Biogeochemical control of phosphorous cycling and primary production in Lake Michigan, Limnol. Oceanogr., 39, 962-968.

Chakraborti, R. K., and J. F. Atkinson (2003), Determination of particle settling rate and characterization of particulate structure using an image analysis method, paper presented at 10th World Lake Conference, 22-26 June, Chicago, Ill.

Eadie, B. J., and S. L. Lozano (1999), Grain size distribution of the surface sediments collected during the Lake Michigan mass balance and environmental mapping and assessment programs, NOAA Tech. Memo., ERL GRERL-111, 4-25.

Eadie, B. J., and J. A. Robbins (1987), The role of particulate matter in the movement of contaminants in the Great Lakes, in Sources and Fates of Aquatic Pollutants, Adv. Chem. Ser., vol. 216, edited by R. Hites and S. Eisenreich, pp. 319-364, Am. Chem. Soc., Washington, D. C.

Eadie, B. J., and J. A. Robbins (2005), Composition and accumulation of recent sediments in Lake Michigan, in State of Lake Michigan: Ecology, Health and Management, Ecovision World Monogr. Ser. edited by T. Edsall and M. Munawas, pp. 89-111, Burlington, Ont., Canada.

Eadie, B. J., R. L. Chambers, W. S. Gardner, and G. L. Bell (1984), Sediment trap studies in Lake Michigan: Resuspension and chemical fluxes in the southern basin, J. Great Lakes Res., 10, 307-321.

Gordon, H. R., and A. Y. Morel (1983), Remote Assessment of Ocean Color for Interpretation of Satellite Visible Imagery, Springer, New York.

Harris, C. K., and P. L. Wiberg (1997), Approaches to quantifying longterm continental shelf sediment transport with an example form the northern California STRESS mid-shelf site, Cont. Shelf Res., 17(11), $1389-1418$

Harris, C. K., and P. L. Wiberg (2001), A two-dimensional, time-dependent model of suspended sediment transport and bed reworking for continental shelves, Comput. Geosci., 27, 675-690.

Jonsson, I. G. (1966), Wave boundary layers and friction factors, paper presented at 10 th International Conference on Coastal Engineering, Tokyo.

Julien, P. Y. (1998), Erosion and Sedimentation, pp. 74-77, Cambridge Univ. Press, New York.

Justesen, P. (1988), Turbulent wave boundary layers, Ser. Pap. 43, Inst. of Hydrodyn. and Hydraul. Eng., Tech. Univ. Denmark.

Kaftori, D., G. Hestroni, and S. Banerjee (1995), Particle behaviour in the turbulent boundary layer I. Motion, deposition, and entrainment, Phys. Fluids, 7, 1095.

Kamphuis, J. W. (1975), Friction factors under oscillatory waves, J. Waterw. Harbors Coastal Eng. Div., 101, 135-144.

Krone, R. B. (1962), Flume studies of the transport of sediment in estuarial processes, final report, Hydraul. Eng. Lab. and Sanitary Eng. Res. Lab., Univ. of Calif., Berkeley.

Lee, C., D. J. Schwab, and N. Hawley (2005), Sensitivity analysis of sediment resuspension parameters in coastal area of southern Lake Michigan, J. Geophys. Res., 110, C03004, doi:10.1029/2004JC002326.
Lesht, B. M. (1989), Climatology of sediment transport on Indiana Shoals, Lake Michigan, J. Great Lakes Res., 13, 486-497.

Lesht, B. M., and N. Hawley (1987), Near-bottom currents and suspended sediment concentration in southern Lake Michigan, J. Great Lake Res., $13,375-386$.

Li, Y., and J. Li (2000), A suspended sediment satellite sensing algorithm based on gradient transiting from water-leaving to satellite-detected reflectance spectrum, Chin. Sci. Bull., 45(10), 925-930.

Liu, P. C., D. J. Schwab, and J. R. Bennett (1984), Comparison of a twodimensional wave prediction model with synoptic measurements, J. Phys. Oceanogr., 14, 1514-1518

Lou, J., D. J. Schwab, D. Beletsky, and N. Hawley (2000), A model of sediment resuspension and transport dynamics in southern Lake Michigan, J. Geophys. Res., 105(C3), 6591-6610.

Mehta, A. J., R. Kirby, J. D. Stuck, J. Jiang, and T. M. Parchure (1997) Erodibility of organic-rich sediments: A Florida perspective, UFL/COEL MP-97/01, 10-11.

Mellor, G. L., and T. Yamada (1982), Development of a turbulence closure model for geophysical fluid problems, Rev. Geophys., 20, 851-875.

Monteith, T. J., and W. C. Sonzogni (1976), U. S. Great Lakes shoreline erosion loadings, pp. 59-60, Great Lakes Basin Comm., Ann Arbor, Mich

National Geophysical Data Center (1996), Bathymetry of Lake Michigan, Rep. $M G G-11$, Boulder, Colo.

Niño, Y., and M. H. Garcia (1996), Experiments on particle-turbulence interactions in the near-wall region of an open channel flow: implications for sediment transport, J. Fluid Mech., 326, 285.

Partheniades, E. (1992), Estuarine sediment dynamics and shoaling processes, in Handbook of Coastal and Ocean Engineering, vol. 3, edited by J. Herbick, pp. 985-1071, Elsevier, New York.

Rao, Y. R., C. R. Murthy, M. J. McCormick, G. S. Miller, and J. H. Saylor (2002), Observations of circulation and coastal exchange characteristics in southern Lake Michigan during 2000 winter season, Geophys. Res. Lett., 29(13), 1631, doi:10.1029/2002GL014895.

Saylor, J. H., J. C. K. Huang, and R. O. Reid (1980), Vortex modes in Lake Michigan, J. Phys. Oceanogr., 10, 1814-1823.

Schwab, D. J. (1983), Numerical simulation of low-frequency current fluctuations in Lake Michigan, J. Phys. Oceanogr, 13, 2213-2224.

Schwab, D. J., and D. Beletsky (2003), The physical mechanisms for offshore transport of bottom sediments during episodic resuspension events in lake Michigan, paper presented at 8th International Conference on Estuarine and Coastal Modeling, Am. Soc. of Civ. Eng.

Schwab, D. J., J. R. Bennett, P. C. Liu, and M. A. Donelan (1984), Application of a simple numerical wave prediction model to Lake Erie, J. Geophys. Res., 89, 3586-3589.

Schwab, D. J., D. Beletsky, and J. Lou (2000), The 1998 coastal turbidity plume in Lake Michigan, Estuarine, Coastal Shelf Sci., 50, 49-58.

Smagorinsky, J. (1963), General circulation experiments with the primitive equations: 1. The basic experiment, Mon. Weather Rev., 91, 99-164.

Smith, J. D., and S. R. McLean (1977), Spatially averaged flow over a wavy bed, J. Geophys. Res., 82, 1735-1746.

Stewart, C. J. (1998), Lake Michigan potential damages study: A revised geomorphic, shore protection and nearshore classification of the Lake Michigan shoreline, U. S. Army Corps of Eng., Detroit District, Mich.

Swart, D. H. (1974), Offshore sediment transport and equilibrium beach profiles, Publ. 131, Delft Hydraul. Lab., Delft, Netherlands.

Tetra Tech, Inc. (1999), EFDC technical memorandum: theoretical and computational aspects of sediment transport in the EFDC model, U.S Environ. Prot. Agency, 12-24.

Torfs, H. (1995), Erosion of mud/sand mixtures, Ph.D. thesis, Catholic Univ. of Leuven, Leuven, Belgium.

van Niekert, A., K. Vogel, R. Slingerland, and J. Bridge (1992), Routing of heterogenous sediments over movable bed: model development, J. Hydrol. Eng., 118(2), 246-263.

Yalin, M. S., and E. Karahan (1973), Inception of sediment transport, J. Hydraul. Div., 99(10), 1679-1704.

D. Beletsky, CILER, SNRE, University of Michigan, Ann Arbor, MI 48105, USA.

C. Lee, Pacific Northwest National Laboratory/Battelle, Marine Science Laboratory, Seattle, WA 98109-3598, USA. (leecheeg@battelle.org)

B. Lesht, Argonne National Laboratory, Argonne, IL 60439, USA.

D. J. Schwab, Great Lakes Environmental Research Laboratory, NOAA, Ann Arbor, MI 48105, USA.

J. Stroud, Department of Statistics, University of Pennsylvania, Philadelphia, PA 19104, USA. 